\title{
SKELETAL ANATOMY OF THE BASICRANIUM AND AUDITORY REGION IN THE METACHEIROMYID PALAEANODONT METACHEIROMYS (MAMMALIA, PHOLIDOTAMORPHA) BASED ON HIGH-RESOLUTION CT SCANS
}

\author{
TIMOTHY J. GAUDIN ${ }^{1, *}$, JOHN R. WIBLE ${ }^{2}$, KENNETH D. ROSE ${ }^{3}$, ROBERT J. EMRY ${ }^{4}$, MICHELLE SPAULDING ${ }^{5}$ \\ 1 Department of Biology, Geology \& Environmental Science, University of Tennessee at Chattanooga, 615 McCallie Ave, Dept. 2653, \\ Chattanooga, TN, 37403-2598, USA; e-mail:Timothy-Gaudin@utc.edu. \\ 2 Section of Mammals, Carnegie Museum of Natural History, 5800 Baum Boulevard, Pittsburgh, PA, 15206, USA; \\ e-mail: wiblej@carnegiemnh.org. \\ ${ }^{3}$ Center for Functional Anatomy and Evolution, The Johns Hopkins University School of Medicine, Baltimore, MD, 21205, USA; \\ e-mail: kdrose@jhmi.edu. \\ ${ }^{4}$ Department of Paleobiology, MRC 121, National Museum of Natural History, Smithsonian Institution, P.O. Box 37012, Washington, D.C., \\ 20013, USA; e-mail: emryr@si.edu. \\ ${ }^{5}$ Purdue Northwest University, Schwarz Hall, 1401 S. U.S. 421, Westville, IN, 46391, USA; e-mail: mspauldi@pnw.edu. \\ * corresponding author
}

Gaudin, T. J., Wible, J. R., Rose, K. D., Emry, R. J., Spaulding, M. (2019): Skeletal anatomy of the basicranium and auditory region in the metacheiromyid palaeanodont Metacheiromys (Mammalia, Pholidotamorpha) based on high-resolution CT scans - Fossil Imprint, 75(3-4): 484-503, Praha. ISSN 2533-4050 (print), ISSN 2533-4069 (on-line).

\begin{abstract}
Cranial skeletal material of the Eocene palaeanodont Metacheiromys marshi was examined using high-resolution CT scans. The present study represents the first time that CT scans have been conducted on skulls of this extinct fossorial mammal. The bony osteology of the auditory region is described in detail, including the ectotympanic and entotympanic, the petrosal in both tympanic and endocranial views, and the middle ear ossicles. The results of this investigation confirm a number of derived resemblances between palaeanodonts and xenarthrans, including a large entotympanic element in the medial wall of the auditory bulla, the presence of an anteroventral process of the tegmen tympani, and a posttemporal canal. However, the present study also provides novel derived auditory features linking palaeanodonts and pangolins, consistent with current understanding of palaeanodont phylogenetic relationships, including the absence of an ectotympanic styliform process, a posterolaterally oriented aperture to the cochlear fossula, and a convex mallear head/concave incudal head. Several autapomorphic features characterizing the auditory osteology of Metacheiromys are also noted. The presence of a large, spherical mallear head, and of a capacious tympanic cavity extended into sinuses in surrounding bones, likely represent adaptations for fossoriality, consistent with palaeobiological inferences drawn from the postcranial anatomy of Metacheiromys.
\end{abstract}

Key words: Metacheiromys, Palaeanodonta, Pholidotamorpha, auditory region, osteology, skull, middle ear ossicles

Received: April 4, 2019 | Accepted: September 17, 2019| Issued: December 30, 2019

\section{Introduction}

Palaeanodonta is a relatively small, extinct group of fossorial, likely myrmecophagous mammals with strongly reduced dentitions (Rose 2006). They are restricted temporally to the Paleogene, and are known geographically across the Laurasian continents, though the best records derive from western North America (Rose 2006, 2008). Previous work variously allied this extinct clade with either the extant placental order Pholidota (the pangolins), the extant clade Xenarthra (armadillos, anteaters, and sloths), or both in the now defunct "Edentata", but a consensus has emerged that they are more closely related to pangolins (Rose et al. 2005, Gaudin et al. 2009). This is supported most recently by a comprehensive analysis of placental phylogeny based on molecular and morphological data (O'Leary et al. 2013).

Partially due to their reduced dentitions, palaeanodonts are uncommon fossils, although many of the taxa are known from skulls and partial skeletons, perhaps because of their burrowing habitus (Rose 2008). The best known taxon, the middle Eocene metacheiromyid palaeanodont genus Metacheiromys, is represented by two different species ( $M$. marshi and M. dasypus; Rose 2008) and multiple, wellpreserved skeletons and skulls. The cranial anatomy was described in detail in Simpson's (1931) comprehensive monograph. The ear region and basicranial anatomy in 

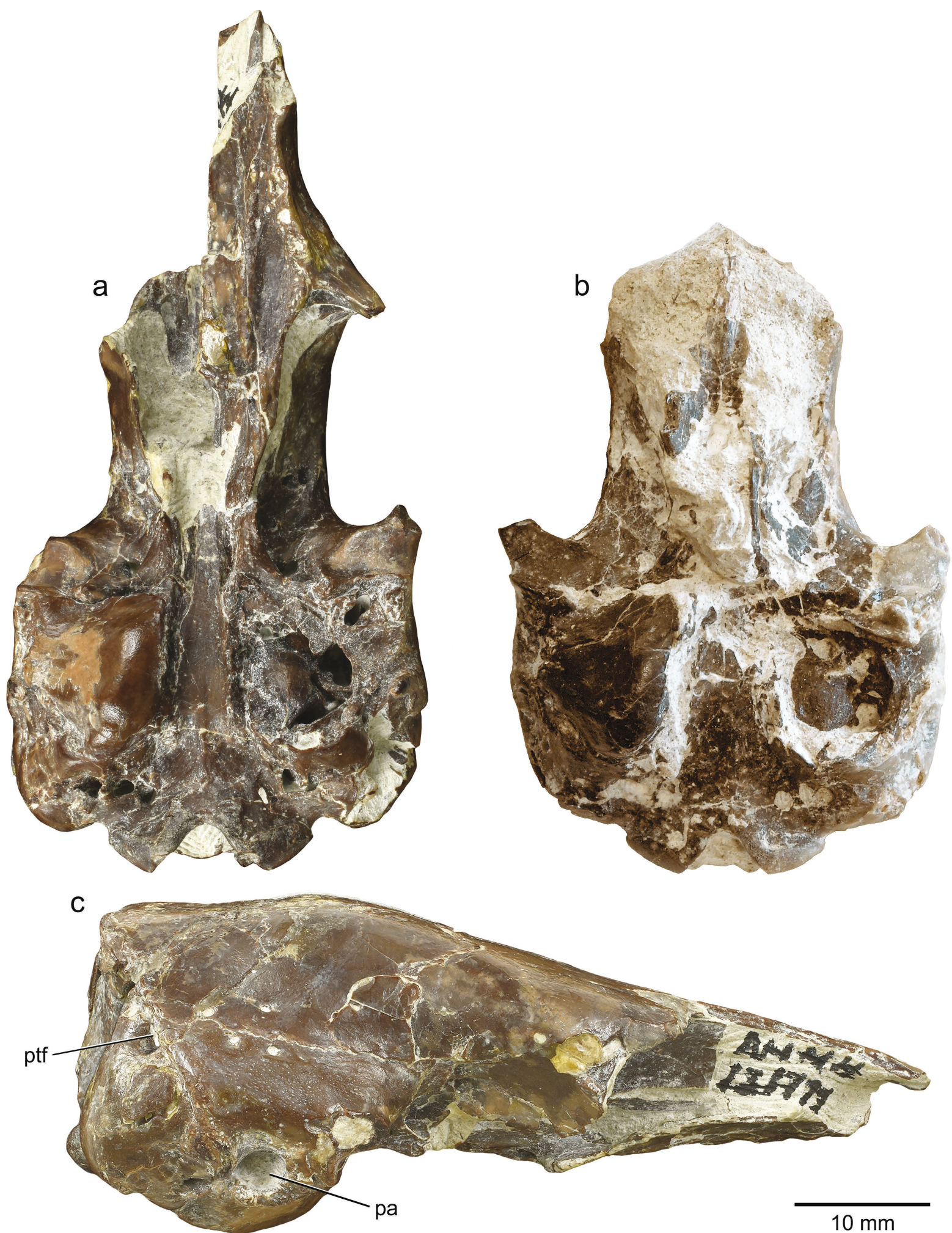

Text-fig. 1. a, c - Metacheiromys marshi, AMNH 131777, skull in ventral, right lateral view; b - Metacheiromys marshi, USNM-P 452349, skull in ventral view. Abbreviations: pa - porus acousticus, ptf - posttemporal foramen.

particular were also described by Patterson et al. (1992), using Simpson's specimens and a newer specimen from the U.S. National Museum that retained preserved ear ossicles. Additional, and in some cases more complete and better preserved cranial material of Metacheiromys is housed in several major U.S. museum collections, but most of this material remains undescribed (e.g. skull illustrated in Rose and Emry 1993: fig. 7.1), although some of these newer specimens have been scored in phylogenetic studies that draw on details from the cranial anatomy of this taxon (e.g. Gaudin 1995, Gaudin and Wible 1999, Gaudin et al. 2009, O'Leary et al. 2013). The present study will focus on one such specimen, a nearly complete skull and skeleton of M. marshi from the American Museum of Natural History. 
Although much anatomical detail from Metacheiromys has been recorded through traditional methods of anatomical study and description, like any fossil taxon, some data remain inaccessible to such methods, in part because of incomplete preservation and postmortem distortion, but also because of incomplete preparation and the difficulty of preparing delicate skull structures and interior skull spaces. Modern CT-scanning technology allows for the extraction of detailed information from fossils that is not typically available from more traditional methods of examination, including the nasal cavity and its delicate nasal turbinate bones (e.g. Fernicola et al. 2012, VanValkenburgh et al. 2014), braincase and cranial sinuses (e.g. Billet et al. 2017, Boscaini et al. 2018), and the inner ear (e.g. Billet et al. 2015). These data can provide new insights not only for comparative anatomy and phylogeny, but also the functional morphology of extinct organisms. Previously, no CT scans of palaeanodont skulls have been published. The goal of the present study is to collect and analyze high-resolution CT-scans of several skulls of Metacheiromys, in order to better assess the bony anatomy of its basicranium and auditory region, and to better understand the phylogenetic, evolutionary, and functional implications of this anatomy.

\section{Materials and methods}

Two specimens of Metacheiromys were micro CTscanned and digitally reconstructed: Metacheiromys marshi, AMNH 131777, and M. marshi, USNM-P 452349 (Text-fig. 1). These skulls were manually compared to other well-preserved Metacheiromys skulls, including $M$. marshi, USNM-P 26132, M. marshi, AMNH 12560, and Metacheiromys sp., YPM-PU 18107. All five skulls derive from the Bridger Formation of Wyoming (Bridgerian NALMA, middle Eocene, 46-50 mya).

The first skull, AMNH 131777, was CT-scanned with a 2010 GE phoenix nano-focus vitomelx s240 at the American Museum of Natural History's Microscopy and Imaging Facility (MIF). We used a beam voltage of $225 \mathrm{kV}$ and produced 1559 16-bit TIFF images, each representing 0.04 millimeters of specimen thickness.

The second specimen, USNM-P 452349, was CTscanned at the University of Chicago Microscopy and Imaging Facility, also using the 2010 GE phoenix nanofocus vltomelx s240kV scanner. Voltage was at $190 \mathrm{kV}$ and 2021 16-bit TIFF images were generated, each representing 0.026 millimeters of thickness.

All slices for both specimens were converted to 8-bit using Adobe Photoshop, cropped and further processed (brightness and contrast) with IMAGEJ, and then imported into AVIZO 9.0 for reconstruction, segmentation, and analysis. All segmentation was done by hand, slice by slice, examining the material in all three directional planes, with no interpolation utilized.

A wide variety of taxa are employed here for comparative purposes. There is information on the auditory osteology of a somewhat older metacheiromyid palaeanodont, the late Paleocene through early Eocene genus Palaeanodon (Rose 2008), which was described and illustrated by Matthew (1918) and Patterson et al. (1992), although the available material is less complete than that of Metacheiromys. Because of the hypothesized sister-group relationship between palaeanodonts and pangolins, we have also used the latter in our comparisons below, both extant taxa and the latest Eocene pangolin Patriomanis americana, which has been described in detail by Gaudin et al. (2016), and is the only fossil pangolin represented by a well-described and illustrated auditory and basicranial region. In addition, because of the previously hypothesized link between palaeanodonts and xenarthrans (Simpson 1931), and in particular the resemblances noted between these forms in their auditory osteology (see Patterson et al. 1992, Gaudin 1995), we have also employed xenarthrans for comparative purposes, in particular the extant armadillos Dasypus and Euphractus, whose auditory and basicranial anatomy is particularly well known (Wible and Gaudin 2004, Wible 2010), and is similar to that of palaeanodonts in a number of respects.

\section{Institutional abbreviations}

AMNH American Museum of Natural History, New York, NY, USA

CM Carnegie Museum of Natural History, Pittsburgh, PA, USA

USNM-P Paleomammal collection, U.S. National Museum of Natural History, Smithsonian Institution, Washington, D.C., USA

UTCM University of Tennessee at Chattanooga Natural History Museum, Chattanooga, TN, USA

YPM-PU Princeton University Collection, Yale Peabody Museum, New Haven, CT, USA

\section{Description}

\section{Overview}

Metacheiromys has a fully ossified auditory bulla including a tubular external acoustic meatus that nearly reaches the lateral margin of the skull (Text-figs 1,2). The primary element of the bulla and tubular meatus is the ectotympanic. Simpson (1931) and Patterson et al. (1992) agreed that another element, the entotympanic, contributed to the bulla, but they disagreed about the size of that element. Simpson (1931) restricted the entotympanic to the medial and anteromedial walls of the bulla, whereas Patterson et al. (1992: 58) extended the entotympanic into the posterior wall, although noting there were only "vague indications of a division between entotympanic and mastoid in this area". The difference in opinion highlights the problem that parts of several basicranial elements are fused in Metacheiromys, as is often the case among adult extant mammals.

Although CT data have provided a new perspective on this problem, they have not miraculously resolved the limits of the basicranial bones in the areas of fusion noted by previous authors. For positing osseous boundaries based on textural differences and morphology in the areas of fusion, we rely more on the study of AMNH 131777 under the microscope, and not the CT scans. Regarding the auditory bulla, sutures on the right side of AMNH 131777 confirm the composition of the bulla in the anterior and nearly the entire 


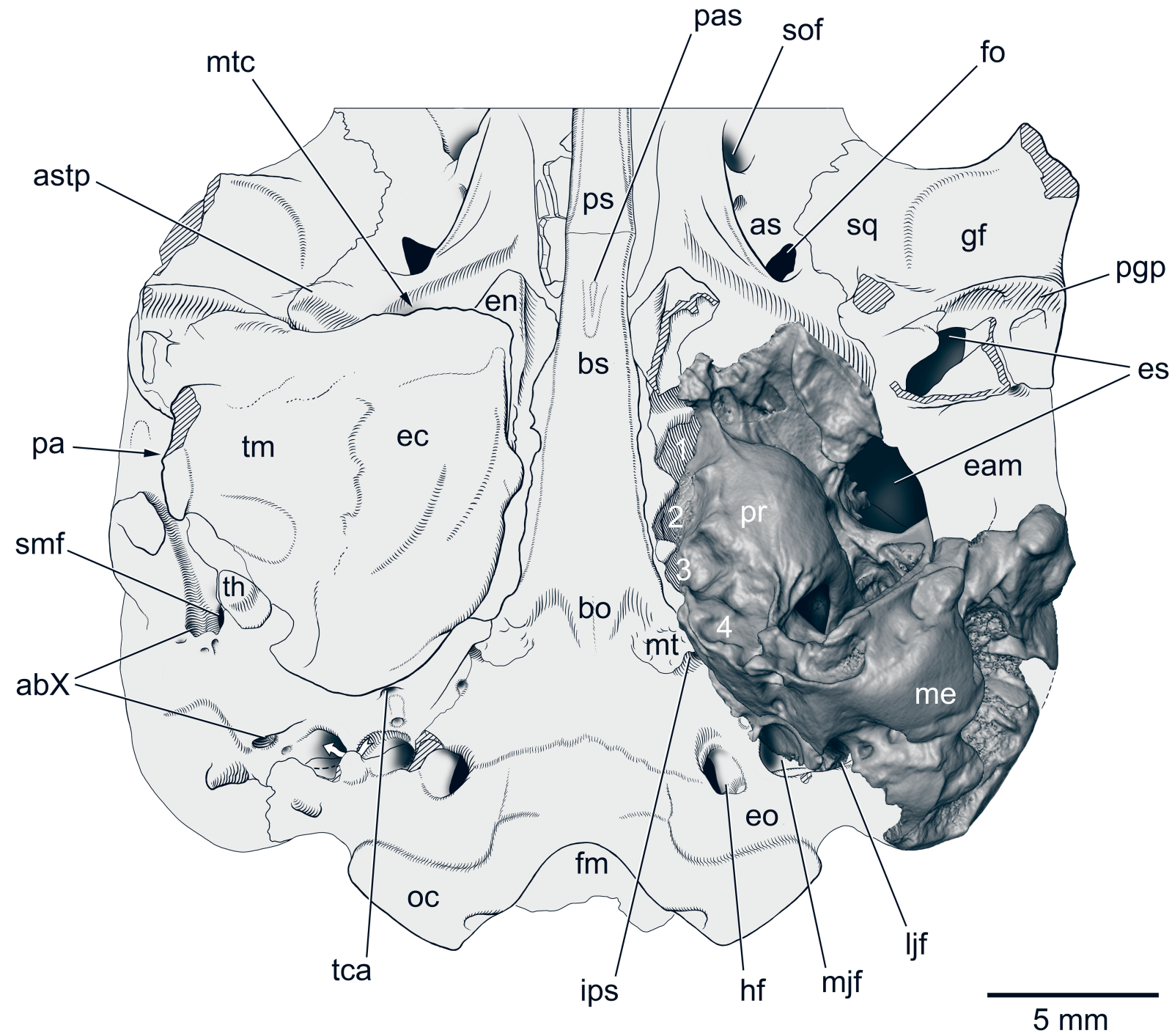

Text-fig. 2. Metacheiromys marshii, AMNH 131777, drawing of basicranium in ventral view with isosurface from CT scans of left petrosal inserted (compare with Simpson 1931: fig. 7). Much of the mastoid exposure on the specimen's left side is damaged. Numbers 1 to 4 indicate depressions that based on the right side include a thin layer of entotympanic; 1 to 3 are between petrosal and basioccipital and 4 is petrosal only. The white arrow in the lower left passes through a canal between the petrosal and exoccipital for the auricular branch of the vagus nerve. Abbreviations: abX - grooves and foramina for auricular branch of vagus nerve, as - alisphenoid, astp - alisphenoid tympanic process, bo - basioccipital, bs - basisphenoid, eam - roof of external acoustic meatus, ec - ectotympanic, en - entotympanic, eo - exoccipital, es - epitympanic sinus of squamosal, fm - foramen magnum, fo - foramen ovale, gf - glenoid fossa, hf - hypoglossal foramen, ips - foramen for inferior petrosal sinus, ljf - lateral jugular foramen, me - mastoid exposure of petrosal, mjf - medial jugular foramen, $\mathrm{mt}$ - muscular tubercle, mtc - musculotubal canal, oc - occipital condyle, pa - porus acousticus (hidden), pas - parasphenoid, pgp - postglenoid process, pr - promontorium of petrosal, ps - presphenoid, smf - stylomastoid foramen, sof - superior orbital fissure, sq - squamosal, tca - tympanic canaliculus, th - tympanohyal, tm - tubular external acoustic meatus.

medial wall; the problem is the posterior wall where there are areas of no sutures or only partial sutures that cannot be fully traced. The issues of fusion in the bulla also confront the primary elements of the tympanic roof, the petrosal and squamosal, mainly in the posterolateral corner of the basicranium. Two other issues complicate our understanding of the basicranium in Metacheiromys. First, the petrosal and squamosal have been highly pneumatized, resulting in the formation of large accessory air chambers in both bones, a squamosal epitympanic sinus (Text-figs 2,3) and a mastoid sinus. Second, there are an excessive number of foramina and canals in the basicranium, more than we have typically encountered in other mammals. Identifying all of these has been challenging.

One observation in AMNH 131777 and USNM-P 452349 outside the ear region that we want to record concerns a low midline crest on the anterior aspect of the ventral surface of the basisphenoid (Text-fig. 2). This crest was also illustrated on the type of Metacheiromys dasypus, AMNH 11718, by Simpson (1931: fig. 5), and is present in 

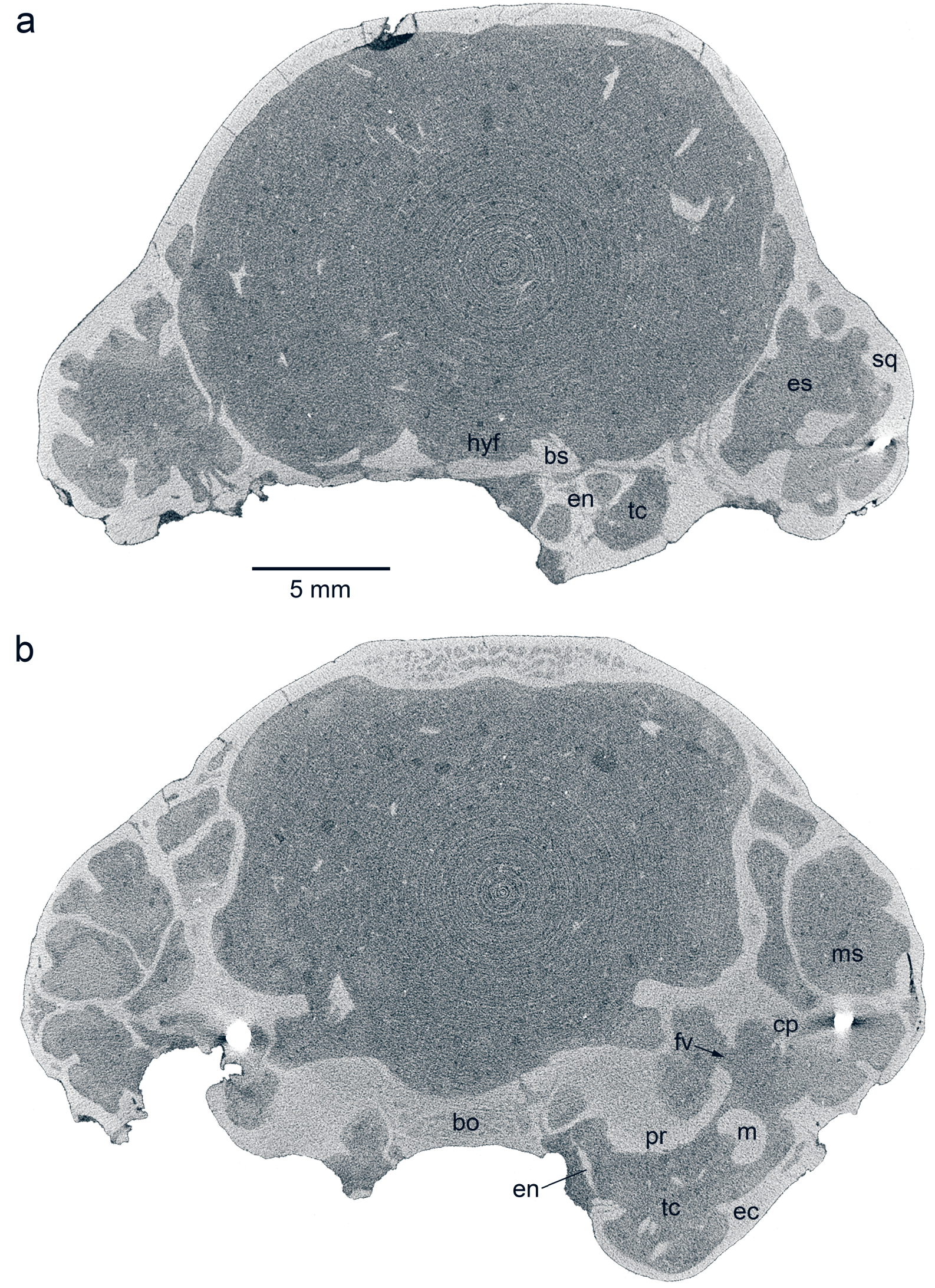

Text-fig. 3. Metacheiromys marshi, USNM-P 452349, coronal sections from CT scans. a - section 590 of 2020 through the anteriormost tympanic cavity showing air spaces in the entotympanic and squamosal; b-section 898 of 2020 at level of the fenestra vestibuli showing the mastoid sinus. Abbreviations: bo - basioccipital, bs - basisphenoid, cp - crista parotica, ec - ectotympanic, en - entotympanic, es - epitympanic sinus of squamosal, fv - fenestra vestibuli, hyf - hypophyseal fossa, $\mathrm{m}$ - malleus, $\mathrm{ms}$ - mastoid sinus, pr - promontorium, sq - squamosal, tc - tympanic cavity. 
M. marshi, USNM-P 26132. Nothing in the CT scans of the two specimens studied here suggests that this is a separate element. Nevertheless, one of the authors of this report has recently published on the occurrence of a little known midline bone called the parasphenoid that occurs in some extant mammals and is thought to be present in some extinct mammals (Wible et al. 2018). We suggest that this midline crest in Metacheiromys likely is a parasphenoid fused to the basisphenoid.

\section{Ectotympanic}

The right auditory bulla is well preserved in both AMNH 131777 and USNM-P 452349, but the left has been largely removed in both specimens to reveal the interior of the tympanic cavity (Text-fig. 1). Regarding the exterior, Simpson (1931) noted the "flask-shaped" auditory bulla, rounded and inflated medially, and extending laterally into a long, tubular external acoustic meatus. The inflated portion of the bulla is longer than it is wide, thus differing from the more spherical shape common among many armadillos (Patterson et al. 1989) and those pangolins with an inflated ectotympanic (e.g. Smutsia temminckii; Gaudin and Wible 1999: fig. 4). The ectotympanic is the primary element of the bulla, as noted by Simpson (1931) and Patterson et al. (1992), and accounts for nearly all of the tympanic floor that is visible in ventral view (Text-fig. 2).
Along its anterior border, the ectotympanic in AMNH 131777 is delimited from medial to lateral by sutures from the entotympanic, alisphenoid, and squamosal, although in the anterolateral corner the ectotympanic is fused to the postglenoid process of the squamosal. The anteromedial margin of the ectotympanic is rounded, without a styliform process, a resemblance to extant pangolins (e.g. Phataginus tetradactyla, CM 7384; Smutsia temminckii; Gaudin and Wible 1999: fig. 4) but unlike armadillos (see Wible 2010: figs 8,9) and other xenarthrans (Patterson et al. 1992). Along its medial border, the ectotympanic in AMNH 131777 is delimited by a roughly horizontal suture from the ventral margin of the entotympanic (Text-fig. 4), except at the posteromedial corner where no suture is evident, although textural differences suggest the continuation of the suture in the same horizontal plane. In the lateral part of the posterior wall, partial sutures appear to delimit the rear of the meatal tube from element(s) that either support it or abut it; the identity of the element(s) is considered below. In the medial part of the posterior wall, sutures are not evident, and we are uncertain if the ectotympanic has a direct contact with the petrosal or if a sliver of entotympanic intervenes.

The lateral opening to the tubular external auditory meatus seems rather small relative to the size of the skull, but it is actually larger in proportion than in either the extant pangolin Phataginus tricuspis or the extant armadillo

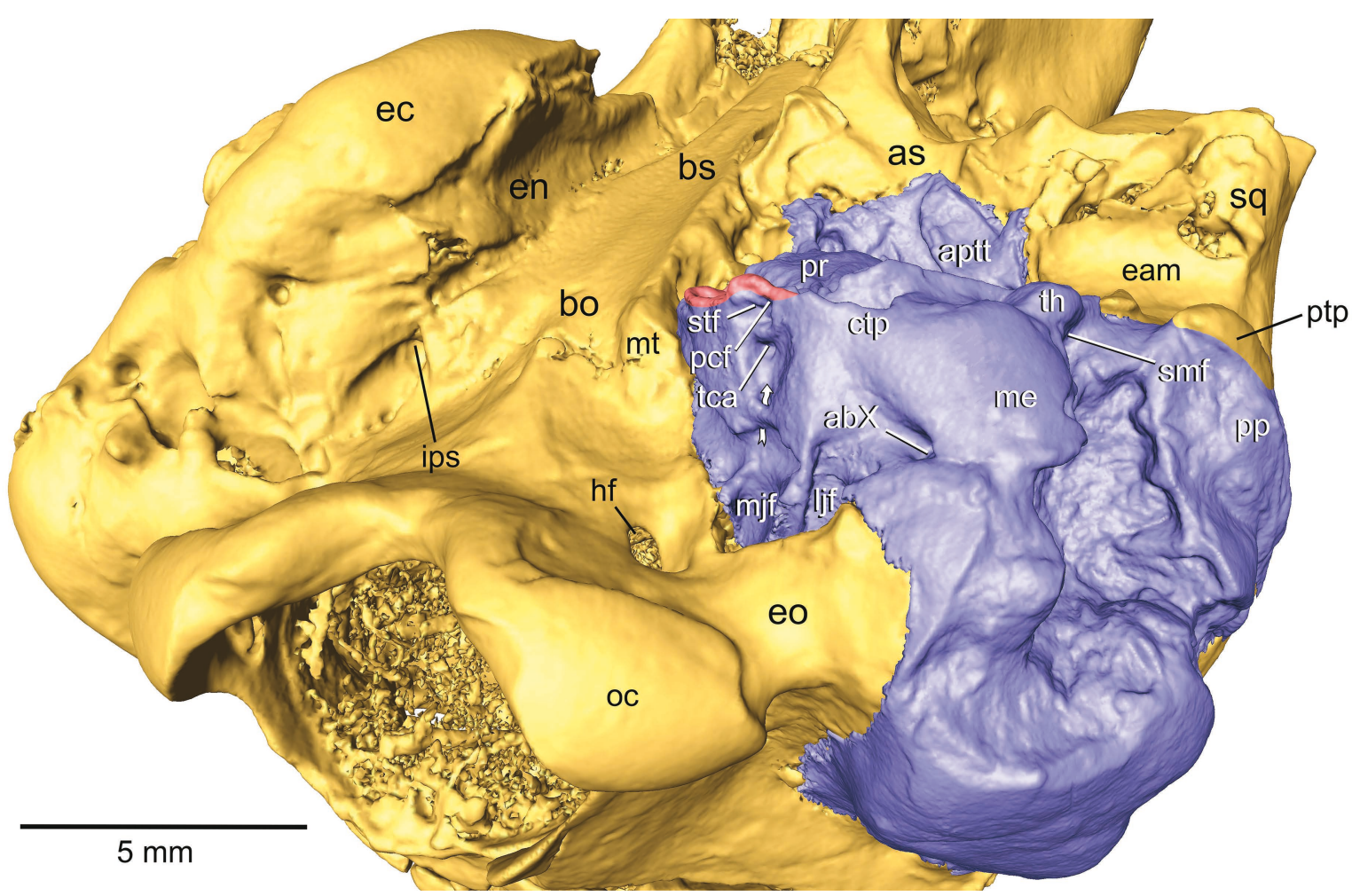

Text-fig. 4. Metacheiromys marshii, AMNH 131777, basicranial isosurface from CT scans in oblique posteroventral view: left petrosal in blue and small piece of left entotympanic in red. The white arrow on the left petrosal passes through a canal traversed by the tympanic nerve. Abbreviations: abX - foramen for auricular branch of vagus nerve, aptt - anteroventral process of tegmen tympani, as - alisphenoid, bo - basioccipital, bs - basisphenoid, ctp - caudal tympanic process, eam - squamosal roof of external acoustic meatus, ec - ectotympanic, en - entotympanic, eo - exoccipital, hf - hypoglossal foramen, ips - foramen for inferior petrosal sinus, ljf - lateral jugular foramen, me - mastoid exposure of petrosal, mjf - medial jugular foramen, mt - muscular tubercle, oc - occipital condyle, pcf - posterior carotid foramen, pp - paroccipital process of petrosal, pr - promontorium of petrosal, ptp - posttympanic process of squamosal, smf - stylomastoid foramen, sq - squamosal, stf - stapedial artery foramen, tca - tympanic canaliculus, th - tympanohyal. 
Table 1. Select skull measurements (mm) of Metacheiromys marshi (AMNH 13177) and comparative taxa. Abberviations: In anteroposterior length, dp - vertical depth.

\begin{tabular}{|l|c|c|c|}
\hline Measurements & $\begin{array}{c}\text { Metacheiromys marshi } \\
\text { AMNH 131777 }\end{array}$ & $\begin{array}{c}\text { Phataginus tricuspis } \\
\text { UTCM 1695 }\end{array}$ & $\begin{array}{c}\text { Euphractus sexcinctus } \\
\text { UTCM 1491 }\end{array}$ \\
\hline Skull & 6.6* & 72.1 & 119.2 \\
Greatest skull length & & & \\
Porus acusticus & 3.3 & 3.8 & 4.4 \\
maximum ln & 2.0 & 1.7 & 4.2 \\
maximum dp & 1.7 & 2.2 & 1.1 \\
ratio ln/dp & & & \\
\hline
\end{tabular}

*missing premaxilla

Euphractus sexcinctus (Tab. 1). It is ovate in shape, elongated anteroposteriorly (Text-fig. 1), as in the former taxon and in contrast to the round opening found in the latter. Additionally, it projects farther laterally at its anterior margin than its posterior one, giving it a slightly oblique orientation in ventral view (Text-fig. 2). From the CT scans of both AMNH 131777 and USNM-P 452349, the bone in the floor of the tubular meatus is as much as 4.5 times thicker than that in the tympanic floor. Also, the internal attachments of the tympanum, the crista and sulcus tympanica, are positioned where the thick tube meets the laminar floor and result in a membrane with an oblique orientation, $50^{\circ}$ to the horizontal.

\section{Entotympanic}

Patterson et al. (1992), Gaudin (1995), and others (e.g. Gaudin et al. 1996, Gaudin 2004, Rose et al. 2005) have noted the strong resemblance between the entotympanic of Metacheiromys and many living xenarthrans, in particular the armadillos (Patterson et al. 1989, Wible and Gaudin 2004), and the strongly contrasting morphology of the element when present in living pangolins, which tends to be small and nodular (Gaudin and Wible 1999). As in some armadillos (e.g. Euphractus sexcinctus; Wible and Gaudin 2004), the entotympanic is the major element in the medial wall of the tympanic cavity of Metacheiromys (Text-figs 3, 4), in which the CT scans of AMNH 131777 and USNM-P 452349 reveal it is a laminar structure wedged between the ectotympanic ventrally and the basioccipital and petrosal dorsally. The entotympanic is primarily concave medially and convex laterally. Euphractus sexcinctus shows the reverse. Sutures delimit the entotympanic in the medial wall in AMNH 131777 except posteriorly, where the bone lies between the ectotympanic and petrosal. In the absence of a suture here, we distinguish the ento- and ectotympanic by their different surface textures, rough and smooth, respectively. A comparable surface textural difference does not distinguish the entotympanic and petrosal, but there is an oblique line of inflection between what we identify as a dorsally convex petrosal and ventrally concave entotympanic. This line passes through a small aperture in the bulla identified below as the posterior carotid foramen, which we reconstruct between the two bones (Text-fig. 4). If our interpretation of the posterior part of the medial bulla wall is correct, the entotympanic tapers in height posteriorly and the petrosal does the reverse, tapering in height anteriorly. The CT scans of the two Metacheiromys also show that the dorsal margin of the entotympanic in the medial wall is infolded laterally
(Text-fig. 3a), again as in Euphractus sexcinctus, with the entotympanic lining four circular depressions in the medial aspect of the promontorium of the petrosal (see petrosal below).

At the anteromedial aspect of the bulla in ventral view in AMNH 131777 is a triangular shaped exposure of the entotympanic, which abuts the basisphenoid anteromedially and the alisphenoid anterolaterally (Text-fig. 2). Although the bone appears thick from the exterior, the CT scans reveal that this part of the entotympanic is hollow (Text-fig. 3a), accommodating an accessory air space confluent with the tympanic cavity posteriorly. The anterolateral margin of the entotympanic here slopes dorsolaterally and ends at an aperture between the entotympanic, ectotympanic, and alisphenoid. This opening is for the musculotubal canal (= Eustachian or pharyngotympanic tube), which connected with the nasopharynx by extending anteroventromedially across the entotympanic and alisphenoid, the latter showing some concavity for the tube (Text-fig. 2). It should be noted here that Gaudin (1995) mistakenly coded the musculotubal canal as lying between ectotympanic, entotympanic and pterygoid in Metacheiromys.

As noted above, it is the composition of the posterior bullar wall that was contentious with prior authors: Simpson (1931) excluded the entotympanic from the posterior wall and Patterson et al. (1992) extended the entotympanic into the posterior wall as far as the tympanohyal, which is situated roughly in the posterior wall's midpoint (Text-figs 2,4). We are not convinced that either view is correct, with the caveat that due to the lack of complete sutures, our interpretation below is taken as tentative until additional information is forthcoming.

For descriptive purposes, we divide the posterior wall in AMNH 131777 into medial and lateral segments with the tympanohyal the divider. In the medial segment, there is little topography to distinguish elements; a faint, horizontal seam, in the same plane as the suture between the ectoand entotympanic in the medial wall on the right side, may delimit two elements, presumably ectotympanic and petrosal, but we cannot rule out the possibility that a sliver of the entotympanic intervenes between the two. In the lateral segment, as seen on the right side, a small, digitiform piece of bone of rougher texture than its neighbors abuts the back of the tubular meatus with some stretches of potential sutures between the two. This digitiform piece in turn underlies a broader, smoother bone dorsally that is certainly petrosal, again with faint indications of potential sutures between the 
a

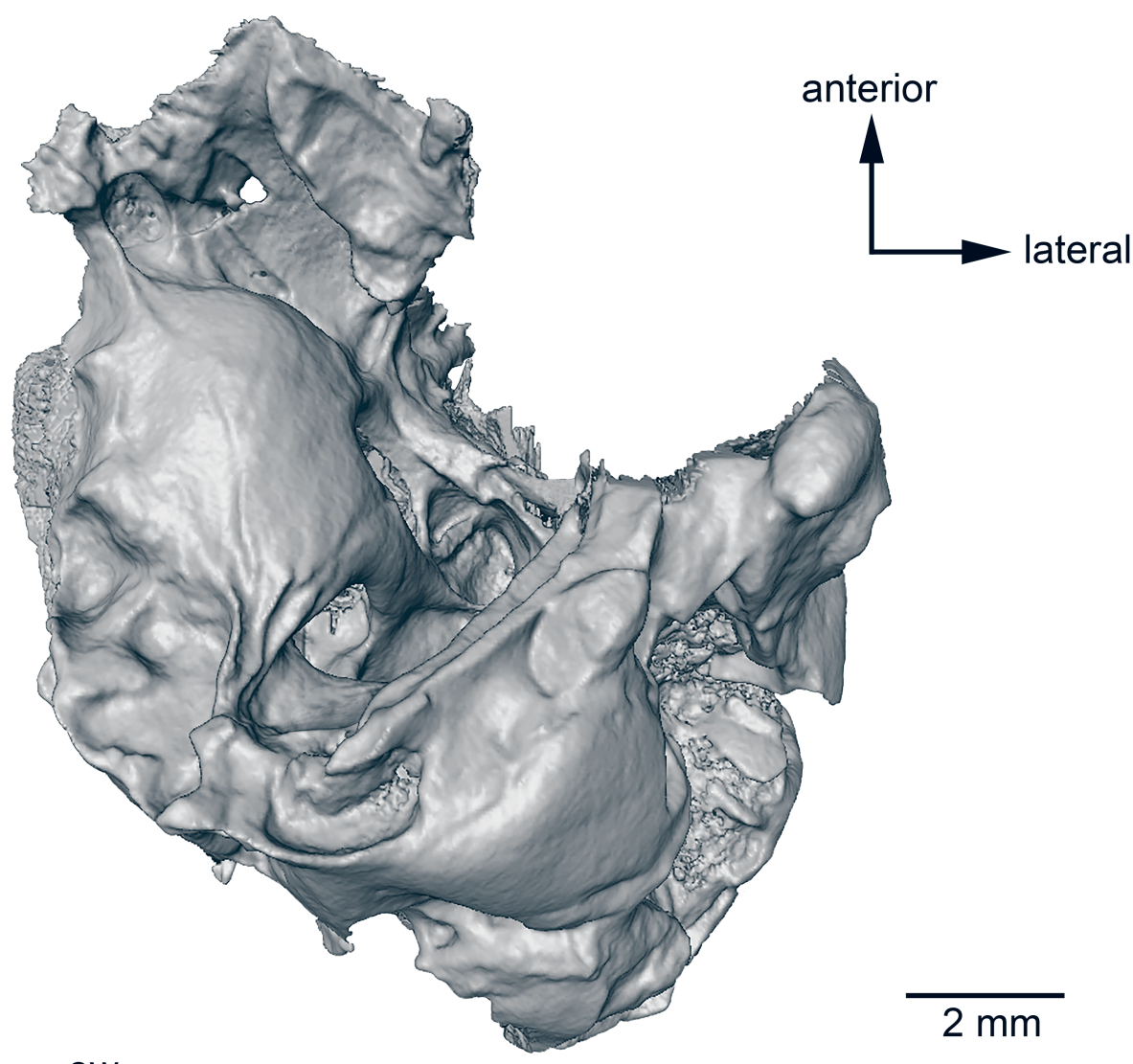

b

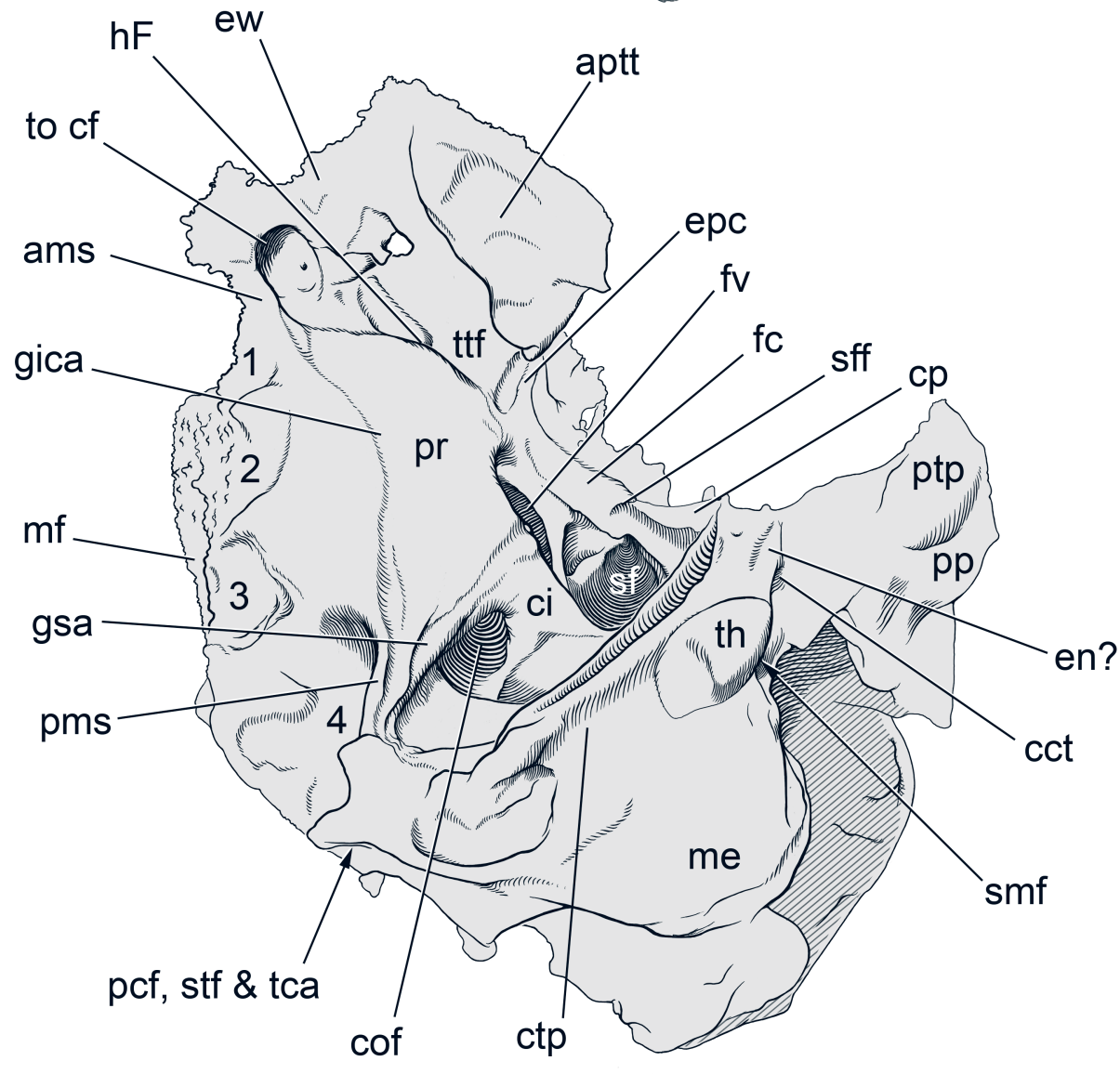

Text-fig. 5. Metacheiromys marshi, AMNH 131777, left petrosal isosurface from CT scans in tympanic view; the posttympanic process of the squamosal and some possible entotympanic are also included. $a$ - isosurface; $b$ - line drawing with labels. Numbers 1 to 4 indicate depressions on medial flange. Abbreviations: ams - anteromedial septum, aptt - anteroventral process of tegmen tympani, cct - canal for chorda tympani nerve, ci - crista interfenestralis, cof - cochlear fossula, cp - crista parotica, ctp - caudal tympanic process, en? - possible entotympanic, epc - epitympanic crest, ew - epitympanic wing, fc - facial canal, fv - fenestra 
two. On the left side where most of the bulla was removed, this sliver of bone is exposed lateral to the tympanohyal. Given the textural differences and the hints of sutures, this sliver of bone is likely the entotympanic. Although it seems likely that the entotympanic in the lateral segment of the posterior wall connected to that in the medial wall, we are currently unable to confirm that. Lateral to the stylomastoid foramen in the lateral segment of the posterior wall is a small, anteriorly directed foramen on both sides of AMNH 131777. On the left side, this foramen can be traced into a short canal that we interpret for the chorda tympani nerve (Text-fig. 5). If the osseous elements are identified correctly here, the course of this canal is fully or partially in the seam between the entotympanic and petrosal.

\section{Petrosal}

Using AMNH 131777, both the actual and virtual (CT scans) fossil, we segmented the left petrosal in Avizo for descriptive and illustrative purposes; this is the side where most of the auditory bulla had been removed prior to our study (Text-figs 2, 4). The areas of greatest uncertainty (and therefore least confidence) for delimiting the petrosal are anteromedially where numerous cracks are present, laterally where most of the sutures with the squamosal are fused, and posteroventrally where an entotympanic may or may not have been present.

The therian petrosal is generally subdivided into the pars cochlearis (for the cochlear duct and saccule) and the pars canalicularis (for the utricle and semicircular canals). As usual, the ventral (tympanic) surface of the pars cochlearis in AMNH 131777 is dominated by the promontorium, the cochlear housing (Text-fig. 5). From the CT scans, the cochlear duct coils through $450^{\circ}$ (following the method in Ekdale 2013). Although often in the same horizontal plane in mammals, the promontorium in AMNH 131777 is positioned such that its rear is ventral to the plane of the basioccipital whereas its anterior pole is well dorsal to that plane. As noted by Patterson et al. (1992), the promontorium is rounded and globose, much more so than that of the older metacheiromyid Palaeanodon, but less than that of the latest Eocene pangolin Patriomanis (Gaudin et al. 2016). However, the former authors also stated that "there is no indication of shelving around the promontorium, as occurs in armadillos" (Patterson et al. 1992: 58). The CT scans reveal that this is not exactly the case, as there is both a medial flange and an epitympanic wing.

The medial flange extends the anteroposterior length of the pars cochlearis (Text-fig. 4) and is more developed than that found in the armadillo Dasypus novemcinctus (Wible 2010), though perhaps not quite as extensive as that of the giant armadillo Priodontes maximus (Patterson et al. 1989) or that of Palaeanodon (Patterson et al. 1992). Patriomanis appears to lack a medial flange entirely (Gaudin et al. 2016). The medial flange in AMNH 131777 is at its widest mediolaterally and thickest dorsoventrally at the posterior end, and tapers in both dimensions towards the anterior pole of the promontorium. Unlike Palaeanodon or armadillos, marking the ventral surface of the medial flange and medial surface of the promontorium are four large, roughly circular depressions, the anterior three of which extend medially onto the basioccipital, the posteriormost being entirely on the petrosal (Text-figs 2, 5). Based on the CT scans of the right sides of AMNH 131777 and USNM-P 452349 where the bulla is in place, these four depressions are lined by a thin layer of entotympanic, which in turn roofs accessory air spaces of the tympanic cavity. At the anterior and posterior ends of this row of four depressions are narrow septa. For descriptive purposes, based on their positions, we identify these as the anteromedial and posteromedial septa.

Extending forward from the anterior pole of the promontorium and lateral to the anteromedial septum is the epitympanic wing, which is not horizontal but downturned anteriorly (Text-fig. 5). This area is quite broken in AMNH 131777 and, therefore, we are not entirely certain of the anterior limit of the epitympanic wing. Immediately lateral to the anteromedial septum is an oval depression, longer than wide, that includes the carotid foramen (see below). Lateral to that is the anterior end of a distinct groove that runs posterolaterally to a foramen, the hiatus Fallopii, for the greater petrosal nerve (Evans 1993, Wible 2010), a branch of the facial nerve; this nerve left the tympanic cavity via the musculotubal canal. Palaeanodon sp. had a more extensive epitympanic wing than Metacheiromys (see Patterson et al. 1992: fig. 18A, B), whereas that in Patriomanis was much less extensive (see Gaudin et al. 2016: fig. 7). Additionally, in both Metacheiromys and Palaeanodon, the epitympanic wing is continuous laterally with the tegmen tympani (see below); this is not the case in Patriomanis or living pangolins (e.g. Phataginus tricuspis, CM 57833, Manis javanica, CM 40597).

One of the more noteworthy discoveries of the present study is the presence in Metacheiromys of a small groove on the promontorium for the internal carotid artery and accompanying nerve (Text-fig. 5). Patterson et al. (1992) claimed that such a groove was missing, despite the presence of a strong transpromontorial groove in the generally more plesiomorphic and older Palaeanodon. They likely missed the presence of the groove because it is very shallow for most of its length, only becoming better defined in its posteriormost reaches, medial to the cochlear fossula. This deeper area was likely either covered by matrix or the entotympanic in previous studies. At the posteromedial corner of the promontorium, the transpromontorial groove runs onto the ventral surface of the posteromedial septum, partially and then fully enclosed in a canal that opens at a small posterior carotid foramen in the bulla wall, which we interpret as between the entotympanic and petrosal. Anteriorly, the transpromontorial groove is more diffuse, but

vestibuli, gica - groove for transpromontorial internal carotid artery, gsa - groove for stapedial artery, hF - hiatus Fallopii, me - mastoid exposure, mf - medial flange, pcf - posterior carotid foramen, pms - posteromedial septum, pp - paroccipital process, pr - promontorium, ptp - posttympanic process of squamosal, sf - stapedius fossa, sff - secondary facial foramen, smf - stylomastoid foramen, stf - stapedial artery foramen, tca - tympanic canaliculus, th - tympanohyal, to cf - to carotid foramen, $\mathrm{ttf}$ - tensor tympani fossa. 
appears to pass lateral to the anteromedial septum towards the oval depression on the epitympanic wing. In the CT scans of both specimens, the bone in this oval depression is damaged, obscuring any evidence for the further course of the internal carotid on the petrosal. However, in the CT scans of USNM-P 452349, anterodorsal to this part of the petrosal, a small carotid foramen penetrates the basisphenoid and opens in the anterolateral aspect of the hypophyseal fossa.

Just lateral to the well-marked portion of the groove for the internal carotid is a second small groove, also well marked posteriorly but becoming shallower anteriorly. This groove is initially parallel to the transpromontorial groove but diverges toward the fenestra vestibuli, representing a groove for the stapedial artery (Text-fig. 5). It reaches the middle of the rim of the fenestra vestibuli and onto a small triangular prominence breaking the plane of the otherwise oval fenestra; this prominence is absent in USNM-P 452349. Posteromedially, the stapedial groove extends onto the posteromedial septum, posterodorsal to the internal carotid. The stapedial groove leads to a canal that opens dorsal to the posterior carotid foramen on the bulla wall at a stapedial foramen (Text-fig. 4), which we interpret as entirely within the petrosal. Given the presence of separate foramina for the internal carotid and stapedial arteries in the bulla wall, the bifurcation resulting in these vessels was outside of the tympanic cavity, an unusual condition in mammals (Wible 1987). In Palaeanodon, the groove for the stapedial artery arises from the internal carotid on the promontorium and is deeper, shorter, and positioned more posteriorly and dorsally (Patterson et al. 1992: fig. 18), relative to that of Metacheiromys. None of the living xenarthrans or pangolins possess a stapedial artery, at least as adults (Guth 1961, Bugge 1979, Wible 1984, 1987), though a reduced artery may be present in juveniles or embyros (Schneider 1955, Wible 1984, Patterson et al. 1992) or in some fossil taxa (Gaudin et al. 2015). Regarding the internal carotid, only vermilinguan anteaters, among the living Xenarthra, possess a transpromontorial internal carotid artery (Guth 1961, Patterson et al. 1992, Gaudin 1995, 2004). In the sloths and cingulates, the artery runs along the ventromedial edge of the petrosal (Guth 1961, Patterson et al. 1989, 1992, Gaudin 1995,2004 ), as it does in pangolins (Kampen 1905, Gaudin and Wible 1999, Gaudin et al. 2009, 2016).

As usual, two large openings are present in the lateral and posterior aspects of the promontorium, the fenestra vestibuli and the aperture of the cochlear fossula, respectively (Textfig. 5). The larger fenestra vestibuli has a stapedial ratio (length to width; Segall 1970) of 1.99 (left side of AMNH 131777) and 1.83 (left side of USNM-P 452349). In comparison, the stapedial ratio of living armadillos is quite similar (1.9-2.0; Wible and Gaudin 2004, Wible 2010), whereas that of sloths and pangolins is somewhat lower (1.51.6; Gaudin 2011, Gaudin et al. 2016). The fenestra vestibuli is directed anteroventrolaterally; the rim accommodating the footplate of the stapes is recessed, producing a shallow vestibular fossula except at its posteriormost aspect. The long axis of the fenestra vestibuli is oblique, from posterodorsal to anteroventral. The other opening, the aperture of the cochlear fossula, is more irregular in shape, like a narrow dome with a straight dorsal side. The cochlear fossula itself is the space between the secondary typmanic membrane, covering the fenestra cochleae, and this aperture in the posterior wall of the promontorium. The aperture is positioned near the posterolateral corner of the promontorium and is directed posterolaterally, a resemblance to Palaeanodon sp. (Patterson et al. 1992: fig. 18), Patriomanis (Gaudin et al. 2016: fig. 7), and living pangolins (e.g. Phataginus tricuspis, CM 57833, Manis javanica, CM 40597). In the dorsal roof of the aperture and extending posteriorly beyond the plane of the aperture is a triangular concavity, the cochlear fossula. The fossula is delimited posteriorly by a tall, thick medial wall and a short, narrow lateral wall. The medial wall is part of the caudal tympanic process described with the pars canalicularis below, which resembles the condition for this process in Smutsia gigantea (CM 5764) and Manis javanica (CM 40597), but not Dasypus (Wible 2010) where the process is broadly separated from the cochlear fossula. Separating the aperture of the cochlear fossula from the fenestra vestibuli in AMNH 131777 is the near vertical crista interfenestralis. The space posterior to the cochlear fossula and crista interfenestralis represents the postpromontorial tympanic sinus.

The parts of the petrosal lateral and posterior to the promontorium in ventral view represent the pars canalicularis, which has been greatly complicated by pneumatization. The course of the facial nerve on the pars canalicularis is a useful point of reference. Commencing at the anterolateral aspect of the fenestra vestibuli is a tubular facial canal (Text-fig. 5), directed posterolaterally, that transmitted the main trunk of the facial nerve from the cavum supracochleare housing the geniculate ganglion within the pars cochlearis. A facial canal is also known to occur in some extant pangolins (Manis javanica, $M$. crassicaudata, and variably present in $M$. pentadactyla and Phataginus tetradactyla; Gaudin and Wible 1999), but is unknown in other pangolins, in armadillos or other xenarthrans, or in Palaeanodon (Patterson et al. 1992). After a $2 \mathrm{~mm}$ course the facial canal opens via the secondary facial foramen into a groove walled laterally by a prominent crest, the crista parotica (Text-fig. 5), most of which is hidden in ventral view on the left side of AMNH 131777 by the squamosal roof of the tubal meatus (Text-fig. 2). The facial groove bends posteroventrally and opens on the exterior at the stylomastoid foramen dorsolateral to the tympanohyal (Text-figs 2, 5). We interpret the stylomastoid foramen as entirely in the petrosal, as in Palaeanodon (Patterson et al. 1992), Patriomanis (Gaudin et al. 2016), and Dasypus (Wible 2010), but in contrast to Euphractus (Wible and Gaudin 2004) and extant pangolins (Jollie 1968), in which the ectotympanic forms a portion of the opening.

The part of the pars canalicularis extending anteriorly from the crista parotica in therians is the tegmen tympani (DeBeer 1929). In AMNH 131777, the posterior part of the tegmen tympani is represented by a low crest, the epitympanic crest (Text-fig. 5), originating from the facial canal, and a shelf anteromedial to it that is continuous with the epitympanic wing described above. Most of this surface is flat except for a small concavity anteromedial and parallel to the epitympanic crest. It is likely that the tensor tympani muscle arose from this entire surface, but the significance of the small concavity on it is enigmatic. A similar, but transversely much broader shelf appears in roughly the same position in Palaeanodon (Patterson et al. 1992). This shelf is 
divided by a crest that runs anteriorly and ventrally. The area medial to this crest is identified by Patterson et al. (1992) as the fossa for the tensor tympani muscle. In Dasypus (Wible 2010), the tensor tympani attaches to the petrosal anterior to the anteroventral process of the tegmen tympani (aptt $=$ processus crista facialis of Patterson et al. 1992, Gaudin 1995), rather than medially or posteromedially, as in palaeanodonts, whereas in Patriomanis, which lacks an aptt, the tensor tympani attaches to the small epitympanic wing of the petrosal and the lateral surface of the promontorium (Gaudin et al. 2016).

Anterior to the epitympanic crest, the tegmen tympani bears an elongate, more ventrally positioned platform (roughly $4 \times 1.5 \mathrm{~mm}$ ) that is obliquely oriented from posterolateral to anteromedial as well as downturned anteriorly (Text-fig. 5). The ventral surface of this platform has an oval depression with a much smaller round depression posterior to it. We identify this platform as the anteroventral process of the tegmen tympani (aptt), which is generally considered to be a synapomorphy of Xenarthra (Gaudin and McDonald 2008). The aptt of Metacheiromys resembles that of Priodontes (Patterson et al. 1989) in size and shape, with the giant armadillo having, proportionally, one of the largest aptt known among extant and extinct xenarthrans. An aptt is not known to occur among any living or extinct pangolins (Gaudin and Wible 1999, Gaudin et al. 2016). However, there is a distinction between the aptt of Metacheiromys and armadillos; in the latter, it provides a contact surface for the ectotympanic (Wible 2010), whereas in the CT scans of both Metacheiromys, the ectotympanic does not abut there. Palaeanodon has a ridge with no platform in the same position that the aptt occurs in Metacheiromys (Patterson et al. 1992).

Adjacent to the crista parotica, facial canal, and epitympanic crest is a large, oval opening between the petrosal and squamosal (Text-fig. 2). This opening, the foramen pneumaticum of Patterson et al. (1992), leads into a much larger space produced by pneumatization of the squamosal bone, including anteriorly over the glenoid fossa, to form an accessory middle ear chamber, an epitympanic sinus (Klaauw 1931). In addition to being a conduit to the epitympanic sinus, the foramen pneumaticum serves as the epitympanic recess, the location of the mallear-incudal articulation (Klaauw 1931). The pars canalicularis forms the anterior, medial, and posterior walls of the epitympanic recess and the medial wall of the dorsally contiguous epitympanic sinus. In the posterior aspect of the epitympanic recess is a small depression on the anterior surface of the crista parotica opposite the position of the secondary facial foramen that represents the fossa incudis, which accommodated the crus breve of the incus (the fossa is hidden by the crista parotica in Text-fig. 5). The dorsal margin of the fossa incudis is marked by a horizontal prominence, the anteriormost part of the gyrus for the lateral semicircular canal. Palaeanodon has a squamosal epitympanic sinus resembling that of Metacheiromys but differs in that the foramen pneumaticum is entirely in the squamosal and the epitympanic recess (labeled tegmen tympani? in Patterson et al. 1992: fig. 18C) is medial to it. An epitympanic sinus is well developed in all extant pangolins, though it tends to extend posteriorly rather than anteriorly into the squamosal (Gaudin 1995,
Gaudin and Wible 1999). It may also be present in the middle Eocene pangolin Eomanis (Rose et al. 2005, Gaudin et al. 2009), but is clearly absent in the late Eocene pangolin Patriomanis (Gaudin et al. 2016). The sinus is variably present in Xenarthra, including euphractine armadillos, anteaters, and most sloths (Patterson et al. 1989, 1992, Gaudin 1995,2004), where it tends to extend anteriorly over the glenoid, as in palaeanodonts.

Posterior to and smaller than the epitympanic recess is an oval depression bounded by the facial canal anteriorly, crista parotica laterally, pars cochlearis medially, and a low crest extending from the crista interfenestralis posteriorly (Textfig. 5). Dorsal to these structures, the remaining part of the gyrus of the lateral semicircular canal is visible bounding the depression. Where the gyrus disappears above the crista interfenestralis, it would have been joined by the gyrus for the posterior semicircular canal. This depression circumscribed by the lateral semicircular canal is subdivided into a larger, deeper posterior part and a smaller, shallower anterior part. The former is the fossa for the stapedius muscle, but we cannot account for the function of the smaller anterior part. The stapedius fossa is deeply impressed and opens almost directly ventrally. Patterson et al. (1992) did not describe the stapedius fossa in Palaeanodon, and from the stereopairs in their paper (fig. 8A-B) we are uncertain of its position. In Patriomanis, the stapedius fossa is very shallow and faces anterolaterally as well as ventrally. It is even more anteriorly oriented in extant pangolins (Gaudin et al. 2016). In xenarthrans, the fossa is also generally shallower with a more lateral orientation (see Gaudin 1995, Wible and Gaudin 2004).

Posterior to the stapedius fossa and the pars cochlearis is a large space produced by pneumatization of the pars canalicularis, the mastoid sinus. This space is not visible in our illustrations but is bounded posteriorly by the bullate mastoid exposure of the pars canalicularis, stretching between the posteromedial septum (and posterior carotid and stapedial foramina) and the roof of the tubal external acoustic meatus. The medial extent of the mastoid exposure is marked by a distinct suture with the exoccipital (Text-fig. 2) that originates at the posterolateral margin of the medial jugular foramen (see description of foramen below). The lateral extent of the mastoid exposure is marked by a suture with the squamosal that follows the line of the nuchal crest but fuses before it reaches the basicranial surface. From the CT scans of both specimens, the mastoid sinus and the squamosal epitympanic sinus communicate broadly deep to the petrosquamous suture on the side of the braincase. According to Patterson et al. (1992), a smaller mastoid sinus is present in Palaeanodon, and it does not communicate with the epitympanic sinus.

Two knobby prominences project from the ventral aspect of the mastoid exposure, a smaller one near the midpoint and a larger one at the lateral extreme (Text-figs 4,5). The smaller prominence, the tympanohyal (hyoid articulation of Simpson 1931), is oval with two subequal ventral surfaces, a rounded anterolateral one and a flatter posteromedial one that lies in an oblique plane (Text-fig. 5); the latter surface has the facet that would have articulated with the stylohyal in life. The larger prominence is digitiform and curved posteroventrally with a small basal heel recessed from the ventral basicranial 
surface. Sutures between the petrosal and squamosal could not be traced in relation to this larger prominence in AMNH 131777. However, the CT scans of USNM-P 452349 reveal that the curved, digitiform process is on the squamosal (labeled as possible squamosal by Simpson 1931: fig. 7), whereas the basal heel is on the petrosal; consequently, we identify the former as the post-tympanic process of the squamosal and the latter as the paroccipital process of the petrosal (Text-figs 4, 5). The paroccipital process lies anterolateral to the distal end of tympanohyal, as is the case in the armadillo Euphractus (Wible and Gaudin 2004) and was probably also the case in Palaeanodon (based on fig. 18 in Patterson et al. 1992, though the paroccipital process is not labeled). In Dasypus (Wible 2010) and Patriomanis (Gaudin et al.2016), the paroccipital process is relatively far posterior or posterolateral to the tympanohyal. As discussed with the entotympanic above, we interpret most of the bone visible on the ventral surface of the mastoid exposure on the left petrosal of AMNH 131777 as petrosal, with the possible presence of some entotympanic posterolaterally. This part of the petrosal represents a greatly inflated caudal tympanic process (Text-figs 4, 5; MacPhee 1981).

Posterodorsal to the medial half of the mastoid exposure is the jugular foramen (posterior lacerate foramen of Simpson 1931 and Patterson et al. 1992) between the petrosal and exoccipital. Although sutures do not delimit the components of the occipital bone, we identify this as exoccipital given its positional relationship to the adjacent hypoglossal foramen, which is generally enclosed in that bone. The jugular foramen on the right side of AMNH 131777 is divided into subequal-sized medial and lateral foramina by septa arising from both the petrosal and exoccipital (Text-fig. 2); the same likely occurred on the left side but there has been some damage. Based on the position of other nervous conduits discussed below, we reconstruct the medial foramen as nervous, transmitting the glossopharyngeal, vagus, and accessory nerves, and the lateral as venous, transmitting the internal jugular vein. Among extant mammals, some (e.g. Homo sapiens; Standring 2008) show a similar positional relationship of structures at the jugular foramen, while others (e.g. Pteropus; Giannini et al. 2006) show the reverse, with the vein anteromedial to the nerves. The jugular foramen in USNM-P 452349 differs in that the opening is only partially divided by a prominence on the petrosal. Simpson (1931: fig. 7) reconstructed only a single jugular foramen for Metacheiromys, and a single foramen is present in USNM-P 26132, whereas in YPM-PU 18107, a single foramen is present on the right, but on the left side of the specimen the foramen is at least partially divided. Only a single foramen is present in Palaeanodon (Patterson et al. 1992), but it is proportionately much larger than that of Metacheiromys.

On the rear of the petrosal ventral and ventrolateral to the jugular foramen, Simpson (1931: fig. 7) noted the presence of four small foramina that he thought were probably vascular. The most medial of these is in the position of the two foramina that we identified above in AMNH 131777 as the posterior carotid and stapedial foramina. AMNH 131777 has a third opening dorsal to these other two that we suggest is for the tympanic nerve, a branch of the glossopharyngeal nerve (Text-figs 2,4). Whatever passed through this third opening came from the medial jugular foramen above and then went through a short, vertical canal in the petrosal before entering the opening next to the posterior carotid and stapedial foramina; the tympanic nerve is the only structure with this course in extant mammals (see Evans 1993: fig. 19-20).

Lateral to the posterior carotid, stapedial, and tympanic apertures, Simpson (1931: fig. 7) labeled another foramen posterodorsal to the tympanohyal; this is also present in AMNH 131777 and is likely vascular. The remaining two foramina of Simpson's four (1931: fig. 7) are also present on the right side of AMNH 131777 but are supplemented by six more. These are related to the convoluted course of the auricular branch of the vagus nerve and accompanying vessel (see Davis and Story 1943: fig. 2). In AMNH 131777, this nerve left the vagus at the medial of the two jugular foramina and ran laterally in a groove on the petrosal in the rim of that foramen. The nerve then went through a canal between the petrosal and exoccipital in the bony strut between the two jugular foramina (Text-fig. 2). Lateral to the lateral jugular foramen are two foramina; we reconstruct the nerve in the larger of these two, while the smaller likely held an accompanying vessel. The lateral opening for this neurovascular bundle is immediately dorsal to the stylomastoid foramen where a small, dumb-bell shaped aperture opens into two grooves passing medial to the posttympanic process of the squamosal. The nerve likely occupied the larger medial groove and the accompanying vessel the smaller lateral groove. One more small foramen opens dorsal to the dumb-bell shaped one and was likely vascular.

The last basicranial foramen we consider lies anteromedial to the medial jugular foramen. It is largely hidden in ventral view, is directed anteriorly, and is bounded medially by the prominent muscular process of the basioccipital and laterally by the petrosal (Text-figs 2,4). This opening corresponds to that described by Patterson et al. (1992: 58) as for the internal carotid artery based on YPM-PU 18107. Given the transpromontorial internal carotid course reported above, this foramen transmitted something other than the internal carotid. It is situated where many mammals have a separate opening for the inferior petrosal sinus (e.g. Monodelphis; Wible 2003; Euphractus; Wible and Gaudin 2004). We were able to trace a canal leading forward from this foramen in USNM-P 452349 initially between the basioccipital and petrosal and then between the basioccipital and entotympanic. However, we were unable to trace it further rostrally due to specimen incompleteness. Nevertheless, the most likely occupant of this foramen and canal is the inferior petrosal sinus. There is an aperture in a similar position in Patriomanis that has also been identified as a foramen for the inferior pertrosal sinus (Gaudin et al. 2016)

The endocranial surface of the petrosal is often overlooked because of accessibility issues and, consequently, is not as well studied as the tympanic surface. With access to the endocranium in the CT scans, we include a description of the endocranial petrosal surface of AMNH 131777 (see Text-fig. 6). The division between the pars cochlearis and pars canalicularis is not as striking in the endocranial view, with the former positioned anteroventromedially and the latter posterodorsolaterally.

The primary feature on the pars cochlearis is the internal acoustic meatus (Text-fig. 6), which is subcircular and deeper than wide, with the transverse crest deeply recessed, 
a

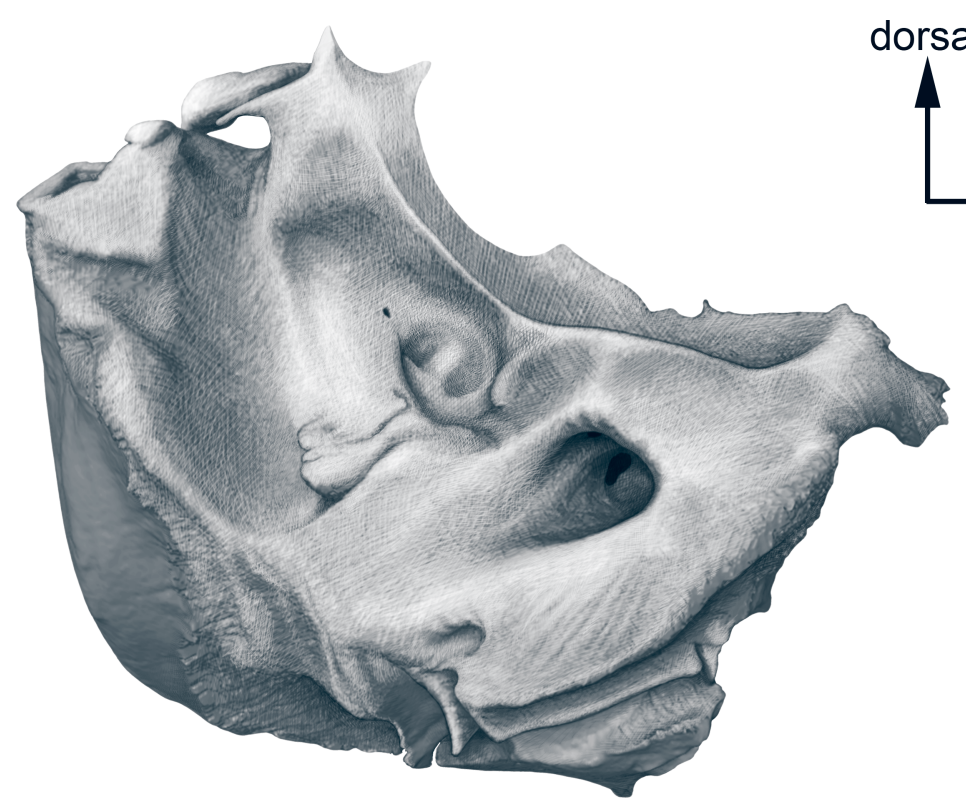

b

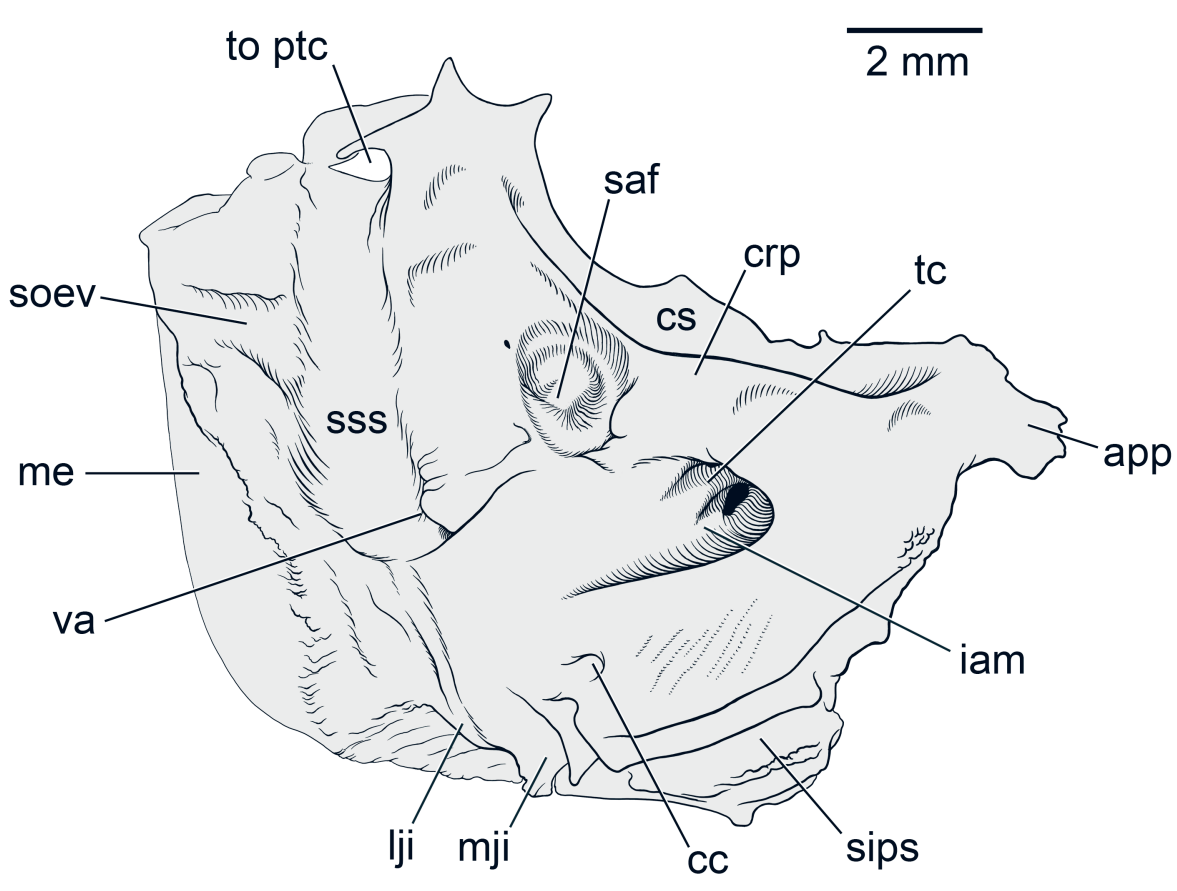

Text-fig. 6. Metacheiromys marshi, AMNH 131777, left petrosal isosurface from CT scans in endocranial view. a - shaded drawing; b - line drawing with labels. Abbreviations: app - apex partis petrosae, cc - cochlear canaliculus, crp - crista petrosa, cs - cerebral surface, iam - internal acoustic meatus, lji - lateral jugular incisure, me - mastoid exposure, mji - medial jugular incisure, saf - subarcuate fossa, sips - sulcus for inferior petrosal sinus, soev - sulcus for occipital emissary vein, sss - sulcus for sigmoid sinus, tc - transverse crest, to ptc - to posttemporal canal, va - vestibular aqueduct.

as it is in extant pangolins (e.g. Smutsia gigantea, CM 5764), but not Dasypus (Wible 2010). Dorsal to the transverse crest is the smaller foramen acusticum superius, which includes the facial foramen anterolaterally and the superior vestibular area posteromedially. Ventral to the transverse crest is the larger foramen acusticum inferius, which includes the spiral cribriform tract medially and the inferior vestibular area posterolaterally; a separate foramen singulare was not discernible but this may have been an issue of scan resolution.
Lateral to the foramen acusticum superius is the prefacial commissure, which is thick with a prominent crista petrosa. The crista petrosa does not contact any bone dorsally as it does in Patriomanis and extant pangolins where it provides the base for the ossified tentorium (Gaudin et al. 2016). The crista petrosa leads anteriorly to a projection from the pars cochlearis, the apex partis petrosae, as occurs in Smutsia gigantea (CM 5764) but not Dasypus (Wible 2010). The broad surface lateral to the crista petrosa contacts the 


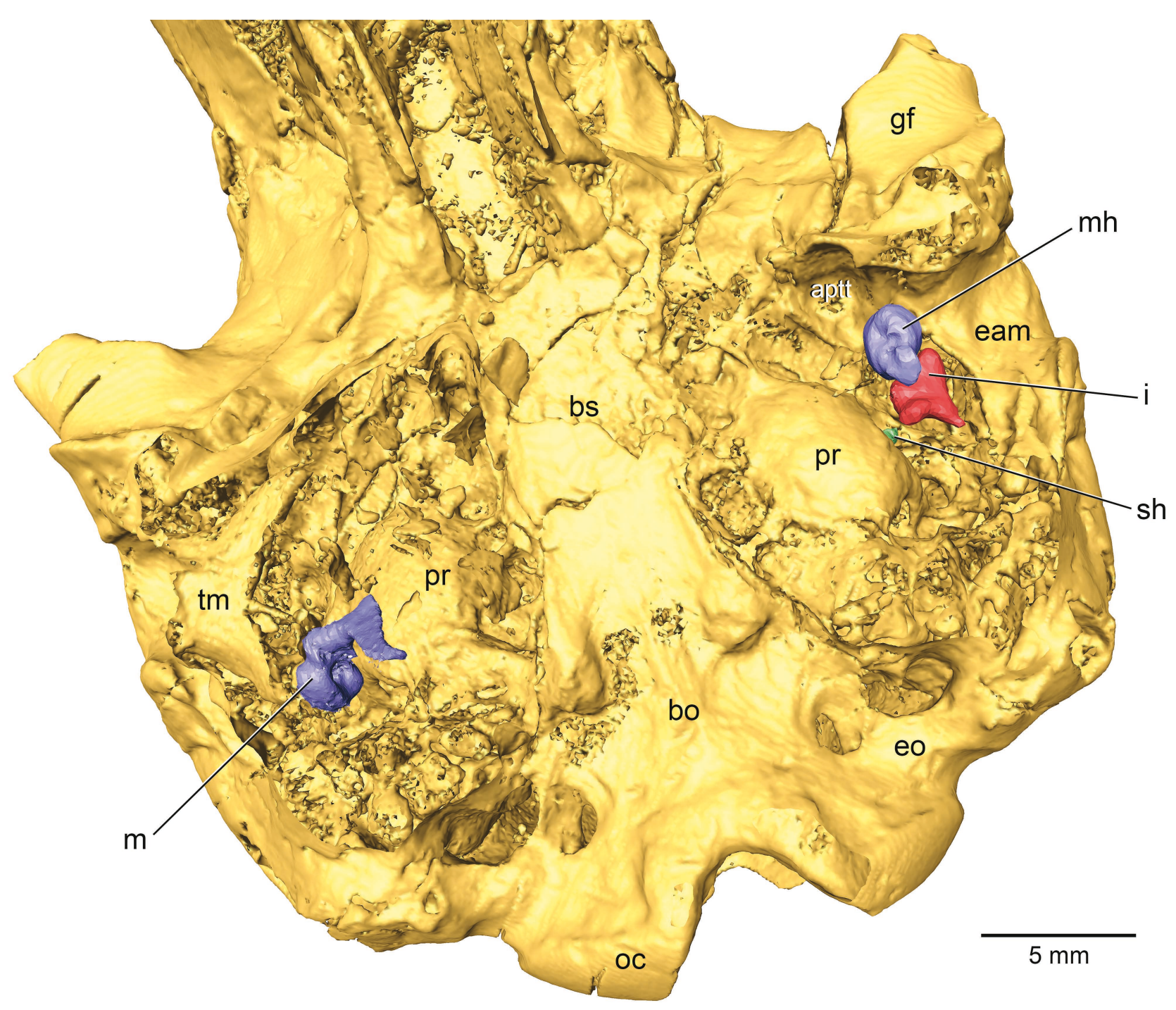

Text-fig. 7. Metacheiromys marshi, USNM-P 452349, basicranium isosurface from CT scans in oblique ventral view, showing middle ear ossicles as preserved. On the specimen's left side, the ossicles are essentially in life position, with the stapes largely hidden in the fenestra vestibuli; the left malleus is broken and represented largely by the mallear head. On the specimen's right side, most of the floor of auditory bulla has been removed to expose the malleus, which has shifted posteriorly from the life position. Abbreviations: aptt - anteroventral process of tegmen tympani, bo - basioccipital, bs - basisphenoid, eam - squamosal roof of external acoustic meatus, eo - exoccipital, gf - glenoid fossa, $\mathrm{i}$ - incus, $\mathbf{m}$ - malleus, $\mathbf{m h}$ - mallear head, oc - occipital condyle, pr - promontorium of petrosal, sh - stapedial head, tm - part of tubular external acoustic meatus.

cerebrum and is formed by the roof of the epitympanic wing anteriorly and the roof of the tegmen tympani posteriorly. Posteromedial to the internal acoustic meatus is the cochlear canaliculus, by which the perilymphatic duct gains entrance to the inner ear.

The primary features on the pars canalicularis are the subarcuate fossa anteriorly and the sulcus for the sigmoid sinus posteriorly, which together occupy most of the visible surface (Text-fig. 6). We are not entirely certain of the limits of the subarcuate fossa, the depression housing the petrosal lobe of the paraflocculus of the cerebellum. If the fossa is defined as the depression circumscribed by the anterior semicircular canal (Gannon et al. 1988), then it is a small, subcircular depression subequal in size to the internal acoustic meatus in AMNH 131777. However, this small depression is part of a larger reniform-shaped space, the boundaries of which are not well defined except along its anterolateral margin, which is formed by the sharp crista petrosa. The anterior margin of this larger space is the prominence posterior to the internal acoustic meatus and the posterior margin is the sulcus for the sigmoid sinus. The subarcuate fossa in Smutsia gigantea (CM 5764) and Dasypus (Wible 2010) is not circumscribed by the anterior semicircular canal and extends onto the neighboring exoccipital and squamosal bones.

Running ventromedially posterior to the subarcuate fossa in AMNH 131777 is the broad sulcus for the sigmoid sinus. Entering the sulcus for the sigmoid sinus from posteriorly is a smaller, horizontal sulcus transmitting the occipital emissary vein (Text-fig. 6). This opens on the occiput at the mastoid foramen between the pars canalicularis and supraoccipital. At the level of the internal acoustic meatus, the sulcus for the sigmoid sinus bends ventrally and continues towards the posterior jugular foramen in a sulcus jointly formed by the pars canalicularis and exoccipital. The sigmoid sinus divides into subequal distributaries: the internal jugular vein runs ventrally out the lateral jugular 
a

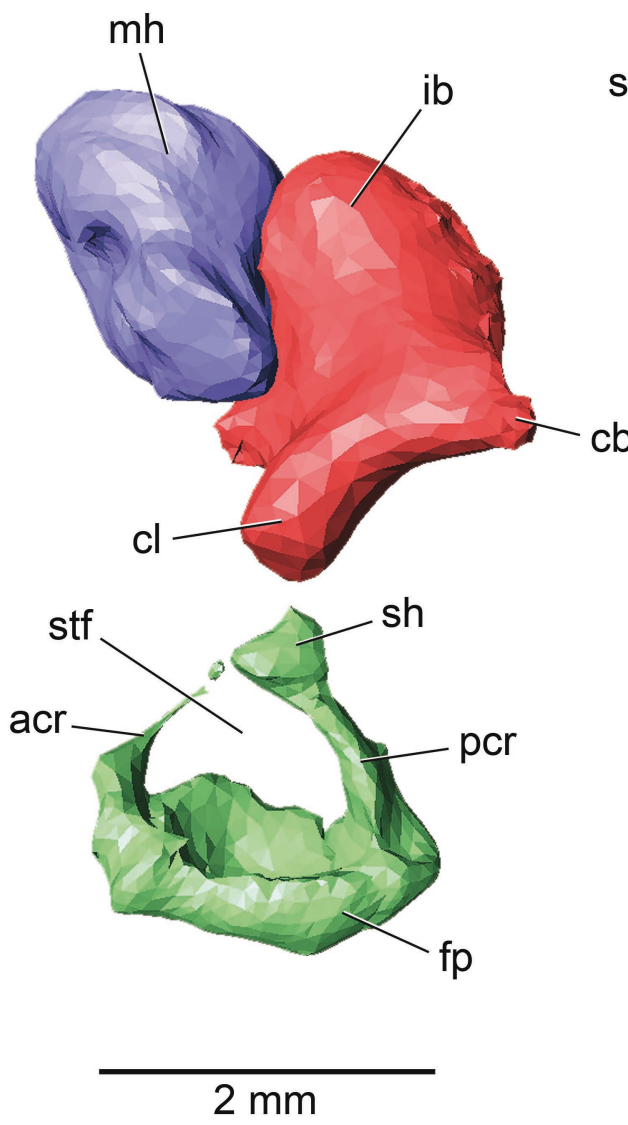

b

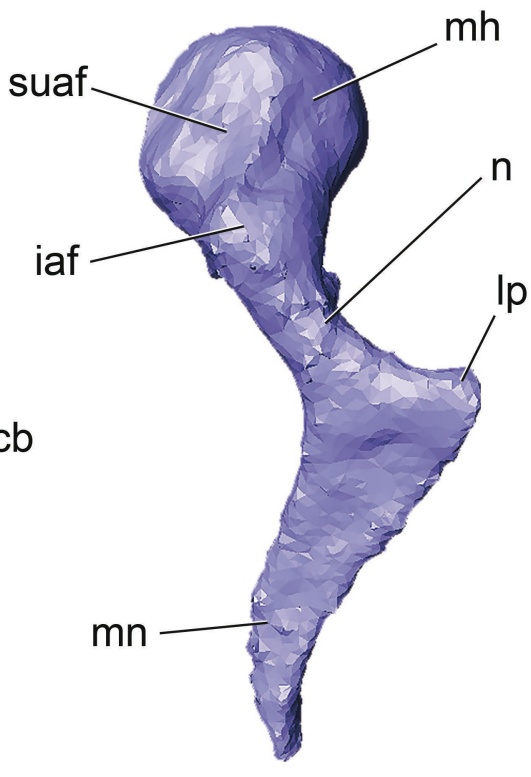

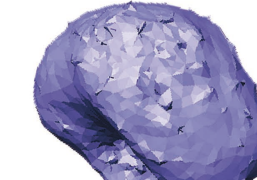

ol

Ip

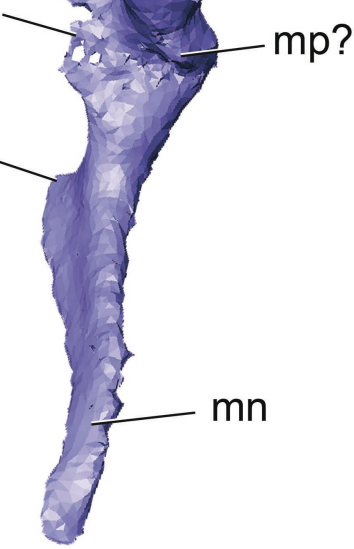

$2 \mathrm{~mm}$

Text-fig. 8. Middle-ear ossicles of Metacheiromys marshi, USNM-P 452349. a - left malleus (partial), incus, and stapes in ventral view; $b$ - right malleus in oblique anterior view (left) and oblique posterior view (right). Abbreviations: acr - anterior crus, cb - crus breve, cl - crus longum, fp - footplate, iaf - inferior articular facet, ib - incudal body, lp - lateral process, mh - mallear head, mn - manubrium, mp - muscular process, $\mathbf{n}$ - neck, ol - osseous lamina (broken), pcr - posterior crus, sh - stapedial head, stf - stapedial foramen, suaf - superior articular facet.

foramen and the condyloid vein runs posteriorly through the condyloid canal in the exoccipital (see Evans 1993). In the anterior wall of the sulcus for the sigmoid sinus at the level of the internal acoustic meatus is the vestibular aqueduct for the endolymphatic duct, hidden by an irregular prominence.

At the top of the sulcus for the sigmoid sinus is a foramen that laterally connects with the posttemporal canal (Text-fig. 6). The well-developed posttemporal canal runs anteroposteriorly and is enclosed between the pars canalicularis and squamosal. Transmitting the arteria diploëtica magna and accompanying vein (Wible 1984, 1987), the canal begins on the occiput at the posttemporal foramen within the pars canalicularis (Text-fig. 1) and continues forward to the orbit. En route to the orbit, the artery and vein provide rami temporales that exit the skull that perfuse the temporalis muscle. AMNH 131777 has five foramina for rami temporales on the right and four on the left, two in the squamosal bilaterally and the remainder in the parietal. A posttemporal canal is present in extant xenarthrans but lacking in extant pangolins (Wible 1984, 1987). AMNH 131777 differs from xenarthrans in that its posttemporal foramen is within the petrosal rather than between the petrosal and squamosal.

\section{Ear Ossicles}

Malleus

The right malleus of USNM-P 452349 is almost fully preserved, with damage to the osseous lamina and associated rostral process. It was found in the epitympanic recess, roughly in situ but most likely rotated medially (Text-figs $7,8)$. Only the head of the left malleus is preserved, still in contact with the incus. Descriptions will be based primarily on the right malleus, as the left preserves no additional structures. On the large rounded head of the malleus there are two facets for articulation with the incus - a larger superior facet that is longer than it is wide and slightly concave, and a smaller, roughly square inferior facet with slight convexity (Text-fig. 8). The superior incudal facet is also larger than the inferior facet in armadillos, but not pilosans, whereas the condition is variable in living pangolins (Segall 1973, Patterson et al. 1992, Gaudin 1995). The angle between the two incudal facets in Metacheiromys is roughly $195^{\circ}$ (measured posteriorly, taking the superior facet as the $0^{\circ}$ line), which is to say, the two form a convex articular surface, as in extant pangolins, whereas in xenarthrans, as in 
other mammals, the incudal facets form a concave surface (Segall 1973, Patterson et al. 1992, Gaudin and Wible 1999, Wible and Spaulding 2012). The vast majority of the mallear head is not covered by the incudal facets, because the head itself is bulbous and spherical, and quite large in proportion to the remainder of the bone. In fact, it is proportionately somewhat larger than the mallear head in living xenarthrans and pangolins (Segall 1973, Patterson et al. 1992), though not as large as that in several taxa of epoicotheriid palaeanodonts (Rose and Emry 1983), in which the mallear head is enlarged as much as in living golden moles (chrysochlorids), which have relative to body size the largest mallear heads among living mammals (Mason 2013).

The manubrium of the malleus in Metacheiromys is relatively long and strongly anteroposteriorly compressed, tapering to a point ventrally, with a flat margin on its lateral apex (Text-fig. 8). The shape is quite similar in Dasypus and Smutsia (Segall 1973, Patterson et al. 1992). The muscular process on the manubrium is not well developed, but the lateral process is much more prominent, ending in a blunt point. A similarly large lateral process is present in pangolins and euphractine armadillos, though not in Dasypus (Segall 1973, Patterson et al. 1992). Only the base of the small, laterally concave osseous lamina is present, as the rest of this thin structure, along with the rostral process, has not been preserved.

\section{Incus}

The left incus of USNM-P 452349 is almost completely preserved, still in articulation with the malleus, with the body of the element housed in the epitympanic recess and the crus breve reaching into the fossa incudis (Text-figs 7,8). There is damage to the crus longum; it is broken before the assumed start of the pedicle, the site of articulation with the head of the stapes. The extreme shortness of the crus breve appears natural, given its preserved position in the fossa incudis. The crus breve is much shorter than the crus longum in cingulates, and is also quite short in Asian pangolins, whereas the two processes are nearly equal in length in sloths and African pangolins (Segall 1973, Patterson et al. 1992). The body of the incus has two articular facets for the head of the malleus. As might be expected given the mallear morphology, the two form a concave articular surface as in extant pangolins, whereas in xenarthrans and other mammals the articular portion of the incudal head is convex (Segall 1973, Patterson et al. 1992, Gaudin and Wible 1999). The lateral articular facet is rectangular, concave, and roughly half the size of the medial articular facet. This latter facet is convex, forming a smooth "c" shape over the body's anterior surface. The very short crus breve extends posteriorly and dorsally from the body to its blunt apex (Text-fig. 8). The base of the crus longum is preserved and shows the element was projected strongly anteriorly with a ventral component. It is broken before any indication of narrowing for the formation of a pedicle. The angle between the two processes is roughly $130^{\circ}$.

\section{Stapes}

The left stapes of USNM-P 452349 is roughly in situ, though it appears to have fallen slightly into the fenestra vestibuli (Text-fig. 7). This ossicle has been partially damaged, with an incomplete anterior crus and a damaged footplate. It was previously described in some detail by Patterson et al. (1992), who noted the low profile of the bone, its width greater than its height, as well as its well-developed stapedial foramen flanked by slightly bowed, laterally convex crura, with an oval, dorsoventrally compressed head and footplate (Text-fig. 8). It is rather similar in form to the stapes of many living placental "insectivores" (Gaudin et al. 1996), lacking the derived modifications that characterize the stapes of extant pangolins and many living and fossil xenarthrans. The scan shows that the footplate is bullate (as in gibbons; see Gaudin et al. 1996), which contrasts with the flat footplate occurring in extant xenarthrans and pangolins (Gaudin et al. 1996).

\section{Discussion}

As noted in the Introduction, the present study is the first publication to employ CT-scanning technology in the study of cranial osteology in Palaeanodonta, and as such we focused on the best known taxon represented by the best preserved cranial skeletal material, the early Eocene (Bridgerian NALMA) metacheiromyid genus Metacheiromys. Although the ear region and basicranium in this taxon have been described by previous authors, notably Simpson (1931) and Patterson et al. (1992), and further detailed information is coded into a number of phylogenetic analyses (e.g. Gaudin 1995, 2004, Gaudin and Branham 1998, Gaudin and Wible 1999, Gaudin et al. 2009, O'Leary et al. 2013), the present study has revealed new details unavailable to prior workers, especially regarding the morphology of the endocranial surface of the petrosal and the morphology of the ear ossicles, and has also allowed us to correct earlier misinterpretations of the auditory anatomy of Metacheiromys, now evident because of the details revealed by this study.

Among the more significant corrections provided by the present study is the documentation of a transpromontorial sulcus for the internal carotid artery. Patterson et al. (1992) asserted that Metacheiromys lacked such a sulcus, in contrast to the older metacheiromyid Palaeanodon, where the groove is quite prominent. The CT scans show that Metacheiromys in fact has a shallow transpromontorial sulcus, along with a shallow sulcus for the stapedial artery (Text-fig. 5). The latter sulcus is also more prominent in Palaeanodon (Patterson et al. 1992). The internal carotid artery enters the tympanic cavity via a posterior carotid foramen between the entotympanic and petrosal in the posteromedial bulla wall (Text-fig. 4). Patterson et al. (1992) claimed that Metacheiromys has a perbullar internal carotid passing through a foramen in the medial wall of the entotympanic. The scans show that this opening actually accommodated the inferior petrosal sinus (Text-figs 2,4).

The new information brought to light by the present study also has important implications for the systematic relationships of palaeanodonts, long a controversial matter. As noted in the Introduction, historically palaeanodonts have been variously allied with the extant mammalian orders Xenarthra and Pholidota (Rose and Emry 1993, Rose et al. 2005). More recently, a consensus has begun to emerge 
favoring the former over the latter (e.g. Gaudin et al. 2009, O'Leary et al. 2013), but the most important data linking palaeanodonts to xenarthrans have come from shared resemblance in their auditory anatomy (Patterson et al. 1992, Gaudin 1995). Our observations confirm a number of unusual resemblances in the auditory osteology of Metacheiromys and xenarthrans. These include a large entotympanic element of similar construction (see Gaudin 1995), an epitympanic sinus inside the squamosal that extends anteriorly toward the glenoid, a distinct, triangular anteroventral process of the tegmen tympani, and a large medial flange of the petrosal. All but the last are quite likely derived relative to the primitive condition for Placentalia (O'Leary et al. 2013). That said, the present study has also uncovered a number of previously unknown, distinctive resemblances between the auditory anatomy of Metacheiromys and that of the living and extinct pangolins, consistent with the recent consensus regarding the sister-group relationship between Palaeanodonta and Pholidota. These new resemblances include the absence of a styliform process of the ectotympanic (commonly present in xenarthrans), an ovate, anteroposteriorly elongated porus acousticus, a posterolaterally oriented aperture to the cochlear fossula, the medial wall of which forms part of the caudal tympanic process of the petrosal, a deeply recessed internal acoustic meatus, an apex partis petrosae, and a mallear/incudal articulation that is convex on the mallear head and concave on the incudal head. Once again, most of these features are likely derived relative to the primitive placental condition (O'Leary et al. 2013; the exceptions being the first and penultimate features). This represents the first time that a significant number of likely derived auditory resemblances between a palaeanodont and pangolins has been identified, consistent with their putative sister-group relationship (Gaudin et al. 2009, O'Leary et al. 2013). Whether these resemblances are actual synapomorphies of these two clades awaits phylogenetic analysis.

The present study also highlights the uniquely derived nature of the auditory osteology in Metacheiromys. Whereas some unique features of this region have long been recognized (e.g. Simpson 1931, Patterson et al. 1992), most prominently, the greatly inflated mastoid portion of the petrosal, many additional potential autapomorphies are identified here for the first time. These include the presence of numerous sinuses, among them not just the squamosal epitympanic and mastoid sinuses, but also sinuses in the dorsal portion of the entotympanic; the presence of a large number of foramina in the basicranium (e.g. associated with the course of the auricular branch of the vagus nerve); the presence of a parasphenoid element fused to the basicranium; an inflated bulla that is elongated anteroposteriorly; the presence of a tubular external auditory meatus; a greater petrosal nerve that exits through the musculotubal canal; stapedial and internal carotid arteries that separate prior to entering the auditory bulla; and, a ventrally directed stapedius fossa. The morphology of the stapes, with its prominent stapedial foramen, and the presence of a transpromontorial internal carotid artery, are likely plesiomorphic aspects of the auditory anatomy (O'Leary et al. 2013).

In addition to the systematic implications of the auditory anatomy in Metacheiromys, it is also the case that some functional inferences can be drawn from this portion of the skull. Metacheiromys, like other palaeanodonts (Rose 2006), has long been ascribed a fossorial lifestyle based on its postcranial skeletal anatomy. The auditory region would seem to confirm such an inference, exhibiting similar fossorially-linked adaptations, most notably an inflated middle ear and an enlarged mallear head (Text-fig. 8). A bulbous mallear head has been previously reported in epoicotheriid palaeanodonts (Rose and Emry 1983), where it is grossly enlarged as in most golden moles (Mason 2003, 2013) and some talpids (Mason 2006). The enlargement of the malleus in these extant subterranean forms is considered an adaptation for the detection of low-frequency seismic vibrations (Mason 2003). The greatly inflated middle ear, including large mastoid and epitympanic sinuses and a sizable ossified auditory bulla, occurs in other subterranean taxa, e.g. kangaroo rats and talpid moles (Webster and Plassman 1992, Mason 2006), where it too has been viewed as an adaptation to perceiving low frequency sound vibrations.

Although much new information has been brought to light by the results of our CT scans, there remains more to learn about the auditory anatomy of palaeanodonts in general, and even Metacheiromys itself. For example, given time and space limitations, the authors chose not to attempt a reconstruction of the bony labyrinth of the inner ear, though the scans of the USNM-P specimen would permit us to do so. Other studies have revealed the important palaeobiological insights that can be gleaned from such reconstructions (e.g. Billet et al. 2015, Ruf et al. 2016, Boscaini et al. 2018 - the last study noted important limitations of such inferences as well), but such insights must await future work. In addition, the scans do not resolve all uncertainties concerning the osteology of the ear region in Metacheiromys. For example, we were unable to resolve the contrasting interpretations of the entotympanic by Simpson (1931) and Patterson et al. (1992), regarding the posterior extent of the element and its contribution to the posterior bullar wall. There are additional well-preserved skulls of Metacheiromys that were inspected visually for the present study, but not scanned, and other well-preserved skulls in other museum collections that were not examined at all. It may be that future detailed studies of this material may help resolve such uncertainties. Moreover, there is less well-preserved but nonetheless interesting cranial material of earlier metacheiromyids, especially of Palaeanodon, and good cranial material as well of the epoicotheriid palaeanodonts (Rose 2006). CT scans and detailed anatomical analysis of these taxa have the potential to add greatly to our knowledge of the systematics, palaeobiology, and evolution of the palaeanodonts as a whole.

\section{Acknowledgments}

We would like to thank the editors for inviting us to participate in this festschrift. Gerhard Storch was an important and accomplished palaeontologist and a valued colleague. Speaking as lead author (TJG), he was not only tremendously helpful in the development of my research, but also unfailingly kind. KDR also acknowledges with gratitude the support, encouragement, and friendship of Dr. Storch over three decades. 
We thank Z.-X. Luo and A. Isch of the University of Chicago, and M. Hill of the American Museum of Natural History (AMNH), for conducting the CT-scans. We thank R. O'Leary and C. Mehling of the AMNH, and J. Strotman and M. Florence of the USNM, for facilitating loans of the Metacheiromys specimens. Text-figs 2, 3 and 4 were skillfully executed by Paul Bowden of the Carnegie Museum of Natural History. This research was supported in part by National Science Foundation Grant DEB 1654949 and the R. K. Mellon North American Mammal Research Institute of the Carnegie Museum of Natural History (JRW), and the Bramblett Gift Fund (TJG).

\section{References}

Billet, G., Hautier, L., Lebrun, R. (2015): Morphological diversity of the bony labyrinth (inner ear) in extant xenarthrans and its relation to phylogeny. - Journal of Mammalogy, 96(4):658-672.

https://doi.org/10.1093/jmammal/gyv074

Billet, G., Hautier L., de Thoisy, B., Delsuc, F. (2017): The hidden anatomy of paranasal sinuses reveals biogeographically distinct morphotypes in the nine-banded armadillo (Dasypus novemcinctus). - PeerJ, 5: e3593 (27 pp.). https://doi.org/10.7717/peerj.3593

Boscaini, A., Iurino, D. A., Sardella, R., Tirao, G., Gaudin, T. J., Pujos, F. (2018 [published online]): Digital cranial endocasts of the extinct sloth Glossotherium robustum (Xenarthra, Mylodontidae) from the late Pleistocene of Argentina: description and comparison with the extant sloths. - Journal of Mammalian Evolution, (17 pp.). https://doi.org/10.1007/s10914-018-9441-1

Bugge, J. (1979): Cephalic arterial pattern in New World edentates and Old World pangolins with special reference to their phylogenetic relationships and taxonomy. - Acta Anatomica, 105(1): 37-46. https://doi.org/10.1159/000145104

Davis, D. D., Story, H. E. (1943): The carotid circulation in the domestic cat. - Fieldiana, Zoology, 28(1): 1-47.

DeBeer, G. R. (1929): The development of the skull of the shrew. - Philosophical Transactions of the Royal Society of London, B, 217: 411-480, pls 94-98. https://doi.org/10.1098/rstb.1929.0009

Ekdale, E. G. (2013): Comparative anatomy of the bony labyrinth (inner ear) of placental mammals. - PLoS ONE, 8(6): e66624 (100 pp.). https://doi.org/10.1371/journal.pone.0066624

Evans, H. E. (1993): Miller's Anatomy of the Dog. - W. B. Saunders, Philadelphia, 1113 pp.

Fernicola, J.C., Toledo, N., Bargo, M. S., Vizcaíno, S. F. (2012): A neomorphic ossification of the nasal cartilages and the structure of paranasal sinus system of the glyptodont Neosclerocalyptus Paula Couto 1957 (Mammalia, Xenarthra). - Palaeontologia Electronica, 15(3): 27A (22 pp.). https://doi.org/10.26879/333

Gannon, P. J., Eden, A. R., Laitman, J. T. (1988): The subarcuate fossa and cerebellum of extant primates: comparative study of a skull-brain interface. - American Journal of Physical Anthropology, 77: 143-164.

https://doi.org/10.1002/ajpa.1330770202
Gaudin, T. J. (1995): The ear region of edentates and the phylogeny of the Tardigrada (Mammalia, Xenarthra). Journal of Vertebrate Paleontology, 15(3): 672-705. https://doi.org/10.1080/02724634.1995.10011255

Gaudin, T. J. (2004): Phylogenetic relationships among sloths (Mammalia, Xenarthra, Tardigrada): the craniodental evidence. - Zoological Journal of the Linnean Society, 140(2): 255-305. https://doi.org/10.1111/j.1096-3642.2003.00100.x

Gaudin, T. J. (2011): On the osteology of the auditory region and orbital wall in the extinct West Indian sloth genus Neocnus Arredondo, 1961 (Placentalia, Xenarthra, Megalonychidae). - Annals of Carnegie Museum, 80(1): 5-29. https://doi.org/10.2992/007.080.0102

Gaudin, T. J., Branham, D. (1998): The phylogeny of the Myrmecophagidae (Mammalia, Xenarthra, Vermilingua) and relationship of Eurotamandua to the Vermilingua. Journal of Mammalian Evolution, 5(3): 237-265. https://doi.org/10.1023/A:1020512529767

Gaudin, T. J., DeIuliis, G., Toledo, N., Pujos, F. (2015): The basicranium and orbital region of the early Miocene Eucholoeops ingens Ameghino, 1887 (Xenarthra, Pilosa, Megalonychidae). - Ameghiniana, 52: 226-240. https://doi.org/10.5710/AMGH.04.12.2014.2755

Gaudin, T. J., Emry, R. J., Morris, J. (2016): Description of the skeletal anatomy of the North American pangolin Patriomanis americana (Mammalia, Pholidota) from the latest Eocene of Wyoming (USA). - Smithsonian Contributions to Paleobiology, 98: 1-102. https://doi.org/10.5479/si.1943-6688.98

Gaudin, T. J., Emry, R. J., Wible, J. R. (2009): The phylogeny of living and extinct pangolins (Mammalia, Pholidota) and associated taxa: a morphology based analysis . - Journal of Mammalian Evolution, 16(4): 235-305. https://doi.org/10.1007/s10914-009-9119-9

Gaudin, T. J., McDonald, H. G. (2008): Chapter 3. Morphology-based investigations of the phylogenetic relationships among extant and fossil Xenarthrans. - In: Loughry, J., Vizcaíno, S. (eds), Biology of the Xenarthra. University of Florida Press, Gainesville, pp. 24-36.

Gaudin, T. J., Wible, J. R. (1999): The entotympanic of pangolins and the phylogeny of the Pholidota (Mammalia). - Journal of Mammalian Evolution, 6(1): 39-65. https://doi.org/10.1023/A:1020538313412

Gaudin, T. J., Wible, J. R., Hopson, J. A., Turnbull, W. D. (1996): Reexamination of the morphological evidence for the Cohort Epitheria (Mammalia, Eutheria). - Journal of Mammalian Evolution, 3(1): 31-79. https://doi.org/10.1007/BF01454253

Giannini, N. P., Wible, J. R., Simmons, N. B. (2006): On the cranial osteology of Chiroptera. I. Pteropus (Megachiroptera: Pteropodidae). - Bulletin of the American Museum of Natural History, 295: 1-134.

https://doi.org/10.1206/0003-0090(2006)295[0001:OTCOOC]2.0.CO;2

Guth, C. (1961): La région temporale des Édentés. - The Author [Imprimerie Jeanne D’Arc], Le Puy, xviiii + 191 pp., 10 pls.

Jollie, M. (1968): The head skeleton of a new-born Manis javanica with comments on the ontogeny and phyloge- 
ny of the mammal head skeleton. - Acta Zoologica, 49: 227-305.

https://doi.org/10.1111/j.1463-6395.1968.tb00155.x

Kampen, P. N. van (1905): Die Tympanalgegend des Säugetierschädels. - Gegenbaurs Morphologisches Jahrbuch, 34: 321-722. https://doi.org/10.5962/bhl.title. 15705

Klaauw, C. J. van der (1931): The auditory bulla in some fossil mammals. - Bulletin of the American Museum of Natural History, 62: 1-352.

MacPhee, R. D. E. (1981): Auditory region of primates and eutherian insectivores. - Contributions to Primatology, 18: $1-282$.

Mason, M. J. (2003): Morphology of the middle ear of golden moles (Chrysochloridae). - Journal of Zoology, London, 260(4): 391-403. https://doi.org/10.1017/S095283690300387X

Mason, M. J. (2006): Evolution of the middle ear apparatus in talpid moles. - Journal of Morphology, 267(6): 678-695. https://doi.org/10.1002/jmor.10430

Mason, M. J. (2013): Of mice, moles and guinea pigs: Functional morphology of the middle ear in living mammals. - Hearing Research, 301: 4-18. https://doi.org/10.1016/j.heares.2012.10.004

Matthew, W. D. (1918): Part V. Insectivora (continued), Glires, Edentata. - In: Matthew, W. D., Granger, W. (eds), A Revision of the Lower Eocene Wasatch and Wind River Faunas. Bulletin of the American Museum of Natural History, 38: 565-657.

O'Leary, M. A., Bloch, J. I., Flynn, J. J., Gaudin, T. J., Giallombardo, A., Giannini, N. P., Goldberg, S. L., Kraatz, B. P., Luo, Z.-X., Meng, J., Ni, X., Novacek, M. J., Perini, F. A., Randall,Z., Rougier, G. W., Sargis, E. J., Silcox, M. T., Simmons, N. B., Spaulding, M., Velazco, P. M., Weksler, M., Wible, J. R., Cirranello, A. L. (2013): The placental mammal ancestor and the post-KPg radiation of placentals. - Science, 339: 662-667. https://doi.org/10.1126/science.1229237

Patterson, B., Segall, W., Turnbull, W. D. (1989): The ear region in xenarthrans (= Edentata: Mammalia) Part I. Cingulates. - Fieldiana, Geology, New Series, 18: 1-46.

Patterson, B., Segall, W., Turnbull, W. D., Gaudin, T. J. (1992): The ear region in xenarthrans (= Edentata: Mammalia) Part II. Pilosa (sloths, anteaters), palaeanodonts, and a miscellany. - Fieldiana, Geology, N. S., 24: 1-79. https://doi.org/10.5962/bhl.title.3466

Rose, K. D. (2006): The Beginning of the Age of Mammals. - Johns Hopkins University Press, Baltimore, 431 pp.

Rose, K. D. (2008): Palaeanodonta and Pholidota. - In: Janis, C. M., Gunnell, G. F., Uhen, M. D. (eds), Evolution of Tertiary Mammals of North America, Vol. 2. Cambridge University Press, New York, pp. 135-146. https://doi.org/10.1017/CBO9780511541438.010

Rose, K. D., Emry, R. J. (1983): Extraordinary fossorial adaptations in the Oligocene palaeanodonts Epoicotherium and Xenocranium (Mammalia). - Journal of Morphology, 175(1): 33-56. https://doi.org/10.1002/jmor.1051750105

Rose, K. D., Emry, R. J. (1993). Relationships of Xenarthra, Pholidota, and fossil "edentates": the morphological evi- dence. - In: Szalay, F. S., Novacek, M. J., McKenna, M. C. (eds), Mammal phylogeny: Placentals. Springer-Verlag, New York, pp. 81-102.

https://doi.org/10.1007/978-1-4613-9246-0_7

Rose, K. D., Emry, R. J., Gaudin, T. J., Storch, G. (2005): Xenarthra and Pholidota. - In: Rose, K. D., Archibald, J. D. (eds), The Rise of Placental Mammals: Origins and Relationships of the Major Extant Clades. Johns Hopkins University Press, Baltimore, pp. 106-126.

Ruf, I., Volpato, V., Rose, K. D., Billet, G., de Muizon, C., Lehmann, T. (2016): Digital reconstruction of the inner ear of Leptictidium auderiense (Leptictida, Mammalia) reveals new insight into leptictidan locomotion. Paläontologische Zeitschrift 90(1): 153-171. https://doi.org/10.1007/s12542-015-0276-2

Schneider, R. (1955): Zur Entwicklung des Chondrocraniums der Gattung Bradypus. - Gegenbaurs Morphologisches Jahrbuch, 95: 209-301.

Segall, W. (1970): Morphological parallelisms of the bulla and auditory ossicles in some insectivores and marsupials. - Fieldiana, Zoology, 51: 169-205. https://doi.org/10.5962/bhl.title.2899

Segall, W. (1973): Characteristics of the ear, especially the middle ear in fossorial mammals, compared with those in the Manidae. - Acta Anatomica, 86: 96-110. https://doi.org/10.1159/000144112

Simpson, G. G. (1931): Metacheiromys and the Edentata. - Bulletin of the American Museum of Natural History, 59(6): 295-381.

Standring, S. (ed). (2008): Gray's Anatomy. 40 ${ }^{\text {th }}$ edition. Churchill Livingstone Elsevier, Edinburgh, 1551 pp.

Van Valkenburgh, B., Pang, B., Bird, D., Curtis, A., Yee, K., Wysocki, C., Craven, B. A. (2014): Respiratory and olfactory turbinals in feliform and caniform carnivorans: the influence of snout length. - Anatomical Record, 297: 2065-2079. https://doi.org/10.1002/ar.23026

Webster, D. B., Plassmann, W. (1992): Parallel evolution of low-frequency sensitivity in Old World and New World desert rodents. - In: Webster, D. B., Popper, A. N., Fay, R. R. (eds), The Evolutionary Biology of Hearing. Springer, New York, pp. 633-636. https://doi.org/10.1007/978-1-4612-2784-7_39

Wible, J. R. (1984): The ontogeny and phylogeny of the mammalian cranial arterial pattern; Ph.D. thesis. - MS, Department of Anatomy, Duke University, Durham, USA, 705 pp. (copy available on-line)

Wible, J. R. (1987): The eutherian stapedial artery: character analysis and implications for superordinal relationships. - Zoological Journal of the Linnean Society, 91: 107-135. https://doi.org/10.1111/j.1096-3642.1987.tb01725.x

Wible, J. R. (2003): On the cranial osteology of the shorttailed opossum Monodelphis brevicaudata (Didelphidae, Marsupialia). - Annals of Carnegie Museum, 72: 137-202.

Wible, J. R. (2010): Petrosal anatomy of the nine-banded armadillo, Dasypus novemcinctus LinNAEUs, 1758 (Mammalia, Xenarthra, Dasypodidae). - Annals of Carnegie Museum, 79(1): 1-29. https://doi.org/10.2992/007.079.0101 
Wible, J. R., Gaudin, T. J. (2004): On the cranial osteology of the yellow armadillo Euphractus sexcinctus (Dasypodidae, Xenarthra, Placentalia). - Annals of Carnegie Museum, 73(3): 117-196.

Wible, J. R., Shelley, S. L., Rougier, G. W. (2018): The mammalian parasphenoid: its occurrence in marsupials.
- Annals of Carnegie Museum, 85(2): 113-164. https://doi.org/10.2992/007.085.0202

Wible, J. R., Spaulding, M. (2012): A reexamination of the Carnivora malleus (Mammalia, Placentalia). - PLoS ONE, 7(11): e50485 (18 pp.).

https://doi.org/10.1371/journal.pone.0050485 